\title{
LOS DERECHOS FUNDAMENTALES Y HUMANOS EN LA CIG'2004*
}

\author{
FRANCISCO JAVIER MATIA PORTILLA \\ Letrado de adscripción temporal del Tribunal Constitucional \\ Profesor de Derecho Constitucional (UVA)
}

SUMARIO

I. Delimitación del objeto de estudio.

II. Los derechos fundamentales en la CIG'2004: ¿Qué hacer con la Carta de los derechos fundamentales de la UE?

III. El contenido de la Carta y de las Explicaciones tras la CIG'2004.

IV. La eficacia de la Parte II TECE: ¿unos derechos y principios que no lo son?

V. Los derechos humanos y la Unión: la adhesión al Convenio Europeo de Derechos Humanos.

VI. Anexo: Listado de documentos de la Convención y de la CIG'2004.

\section{DELIMITACIÓN DEL OBJETO DE ESTUDIO.}

La Conferencia de los Representantes de los Gobiernos de los Estados Miembros aprobó, en la reunión celebrada en Bruselas el pasado 18 de junio de 2004, la versión del Tratado por el que se instituye una Constitución para Europa que se someterá a la consideración de los distintos Jefes de Estado o de Gobierno para su eventual adopción

* Algunas de las ideas que se incluyen en este estudio fueron adelantadas en la conferencia sobre "La Carta Europea de Derechos Fundamentales", impartida en el VI Curso de Verano sobre la Unión Europea del Instituto de Estudios Europeos de la Universidad de Valladolid el pasado 16 de julio, dentro del módulo Jean Monnet 2004. Agradezco a los promotores del citado evento, y a los responsables de Teoría y Realidad Constitucional, su invitación a reflexionar sobre tales materias, en esta contribución que se inscribe en las tareas del grupo de investigación sobre La Convención Europea 2002-2003. El futuro funcional e institucional, dirigido por A. Calonge Velázquez. 
siones en esta sede se hayan centrado, fundamentalmente, en el reparto del poder en el Consejo de Ministros de la UE, sin que hayan alcanzado mayor repercusión pública los avances experimentados en lo que afecta a los derechos fundamentales de la Unión Europea y a los derechos humanos que, en el plano internacional, la Unión se podría comprometer a respetar en el futuro.

Este es, precisamente, el objeto del trabajo que el amable lector tiene entre sus manos. Aunque de lo ya expuesto se colige, con cierta nitidez, que el uso de los términos elegidos (derechos fundamentales y derechos humanos) alude a realidades bien distintas, es oportuno aclarar, para conjurar cualquier interpretación equívoca, que con el primer término se alude a los derechos fundamentales reconocidos y garantizados por la propia Unión Europea, mientras que el término derechos humanos, polisémico, lo usamos, en estas líneas, haciendo referencia a la eventual vinculación de la Unión Europea a un sistema internacional de protección de los derechos (a través de la eventual adhesión, como veremos, al Convenio Europeo de Derechos Humanos).

La naturaleza de una y otra cuestión es bien distinta, aunque tal extremo pueda haber sido obviado porque ambas se haya planteado conjuntamente a la Convención. En efecto, el Consejo Europeo se interesó en que la misma se pronunciara sobre «si la Carta de Derechos Fundamentales debe integrarse en el tratado básico y plantearse la cuestión de la adhesión de la Comunidad Europea al Convenio Europeo para la protección de los derechos humanos» (Ibídem, p. 24).

Para afrontar la tarea que la Convención tenía que abordar, mucho más amplia que la descrita en el presente estudio, ésta ha optado por organizar sus trabajos a través de diversos Grupos de Trabajo, dedicando uno de ellos (el segundo) a la «Integración de la Carta y adhesión al CEDH» ${ }^{1}$, lo que nos obliga a examinar, de forma detallada, tanto los documentos generados en su seno como aquellos documentos de trabajo de los que se ha valido $^{2}$.

\section{LOS DERECHOS FUNDAMENTALES Y LA CIG'2004: ¿QUÉ HACER CON LA CARTA DE DERECHOS FUNDAMENTALES DE LA UE?}

Es forzoso hace notar que, como no puede ser de otra forma, el Consejo Europeo parte ya de la existencia de la denominada Carta de Niza, que había sido elaborada por «un órgano en el que participen delegados de los Jefes de Estado y de Gobierno y del Presidente de la Comisión Europea y miembros del Parlamento Europeo y de los Parlamentos nacionales» ${ }^{3}$. Aunque el Consejo Europeo se referiría a este foro como órgano competente para la tarea encomendada ${ }^{4}$, el mismo se rebautizaría a si mismo con el nombre de Convención. Producto de esta primera Convención fue la Carta de los derechos fundamentales de la Unión Europea, documento que fue proclamado de forma solemne por los Presidentes del Parlamento Europeo, del Consejo y de la Comisión con ocasión del Consejo Europeo de Niza, el 7 de diciembre de 2000. Precisamente, en ese mismo lugar, se preguntaban los Jefes de Estado y de Gobierno cuál debería ser el estatuto jurídico que debía conferirse a la Carta.

Es oportuno aclarar que no haremos referencia, en las siguientes líneas, a la problemática de los derechos fundamentales en la Unión Europea, que ha conocido una muy interesante evolución desde los años sesenta hasta el momento actual ${ }^{5}$. Por otra parte, en 
(CIG 85/04, PRESID 26). De esta forma se pone fin, en principio, a la labor que la Conferencia Intergubernamental (CIG'2004) tenía encomendada.

En esta ocasión, el trabajo de la CIG era más limitado que en ocasiones anteriores, ya que el borrador o proyecto de Tratado de reforma del Derecho originario de la Unión Europea (UE en adelante) había sido encargado a un órgano específico, denominado Convención, compuesto por un Presidente, dos Vicepresidentes, quince representantes de los Jefes de Estado o de Gobierno de los Estados miembros y candidatos (uno por cada Estado), dos miembros por cada uno de los Parlamentos nacionales de los Estados miembros y candidatos — si bien los representantes de los Estados candidatos no pueden impedir el consenso que pueda alcanzarse entre los Estados miembros-, dieciséis miembros del Parlamento Europeo y dos representantes de la Comisión, y un número idéntico de suplentes. Por su parte, el Praesidium de la Convención se compone del Presidente, los dos Vicepresidentes y nueve de sus miembros (los representantes de todos los gobiernos que durante la Convención ostenten la Presidencia del Consejo, dos representantes de los Parlamentos nacionales, dos representantes de los diputados del Parlamento Europeo y dos representantes de la Comisión). También se contempla la intervención, en calidad de observadores, de tres representantes del Comité Económico y Social, de tres representantes de los interlocutores sociales europeos, de seis representantes del Comité de las Regiones (designados de entre las ciudades y las regiones con competencia legislativa) y del Defensor del Pueblo Europeo ( $c f r$. Anexos de las Conclusiones de la Presidencia del Consejo Europeo de Laeken, celebrado los días 14 y 15 de diciembre de 2001 —SN 300/1/01 REV 1, pp. 24 y 25-).

La irrupción de este novedoso órgano ad hoc o específico permite diferenciar dos fases distintas en la gestación de la reforma de los Tratados: una primera, debida a los trabajos desarrollados por la Convención y otra, marcadamente política, en la que los representantes de los Gobiernos de los Estados Miembros han resuelto aquéllas cuestiones que suscitaban determinadas reservas nacionales. En este sentido, no deja de ser llamativo que las discu-

1 La «Nota sobre los métodos de trabajo», dirigida por el Praesidium a la Convención el 14 de marzo de 2004, prevé la posibilidad de que se articulen grupos de trabajo (art. 15: «Habida cuenta de los puntos de vista expresados en la Convención, el Presidente o un número significativo de los miembros de la Convención podrá recomendar que el Praesidium establezca grupos de trabajo de la Convención. El Praesidium determinará su mandato, métodos de trabajo y composición, teniendo en cuenta los conocimientos específicos de los miembros titulares y suplentes y de los observadores con respecto al tema de debate. Cualquier miembro de la Convención podrá asistir a todas las reuniones de estos grupos. La Secretaría elaborará una nota resumida tras cada reunión de los grupos de trabajo») (CONV 9/1/02, REV 1, p. 7). En el posterior documento CONV 52/02, de 17 de mayo, se prevé la existencia del Grupo II (»Si se decide introducir la Carta de Derechos Fundamentales en el Tratado: ¿de qué modo debe hacerse y cuáles serían las consecuencias? ¿Qué consecuencias tendría la adhesión de la Comunidad o de la Unión al Convenio europeo de derechos humanos?, p. 2) que será presidido por António Vitorino. Los restantes miembros del Grupo de Trabajo son dados a conocer en el documento CONV 77/1/02 REV 1, de 14 de junio, p. 3. Por otra parte, el Mandato del Grupo «Carta» puede consultarse en CONV 72/02, de $31 / 05 / 2002$.

2 Los documentos han sido listados en un anexo al presente estudio.

3 Decisión del Consejo Europeo relativa a la elaboración de una Carta de Derechos Fundamentales de la Unión Europea, que figura como anexo IV de las Conclusiones de la Presidencia del Consejo Europeo de Colonia, de 3 y 4 de junio de 1999.

4 Vid Anexo a las Conclusiones de la Presidencia del Consejo Europeo de Tampere, celebrado los días 15 y 16 de octubre de 1999 . 
opciones c, e y f confieren carácter plenamente vinculante a la Carta (ibídem, p. 8). Por otra parte, es igualmente evidente que algunas de las formas propuestas son complementarias entre sí (esto ocurre, por ejemplo, con las dos primeras).

Dos ideas se imponen, con cierta rapidez, en el seno del Grupo: (a) la Carta debe integrarse en los Tratados (b) a través de la plena introducción de su articulado en un lugar relevante de estos —opción f)—. En efecto, los miembros del Grupo de trabajo se han decantado, desde el primer momento, por la inclusión del contenido íntegro de la Carta en los Tratados, por razones de visibilidad y transparencia (reunión de 12/07/2002, WG II 7, p. 2), aunque otras voces defienden que la decisión de la técnica de integración es política (y supera los cometidos encargados al foro en el que se encuentran) y otros asistentes defienden el interés del texto como una declaración (ídem), dejándose también la puerta abierta a soluciones intermedias —ibidem, p. $3-^{7}$ ).

Como era de esperar, todos los miembros del Grupo o apoyan firmemente la incorporación de la Carta mediante una fórmula que le permita ser jurídicamente vinculante y tener un estatuto constitucional o no descartan dar una consideración favorable a dicha incorporación (WG II 16, p. 2), en el Informe final (Informe, desde este momento) del Grupo II, que fue aprobado en la reunión celebrada el 21 de octubre de 2002 (cfr. WG II 17) y presentado un día más tarde. Tal material debería presentar, en todo caso, realce constitucional (ídem), ya sea incluyendo el texto —opción mayoritaria, que configuraría la carta como un texto jurídicamente vinculante de carácter constitucional-, o una referencia (que podría combinarse con la inclusión en el Tratado o en un Protocolo anejo) u optando por una referencia indirecta (ibídem, p. 3, que se remite al documento CONV 116/02, p. 7). En todo caso, la forma concreta de incorporación depende del marco general de la arquitectura del Tratado que se plantee el pleno de la Convención.

La decisión final, contenida en el Tratado por el que se establece una Constitución para Europa (TECE en adelante ${ }^{8}$ ) se explicita en el art. I-9.1, que dispone que «La Unión reconoce los derechos, libertades y principios enunciados en la Carta de los Derechos Fundamentales que constituye la Parte II». En todo caso, la decisión de que el articulado de la Carta forme parte de los Tratados comunitarios plantea algunos interrogantes sobre los que ha debido pronunciarse el Grupo de Trabajo II y la propia Convención en la que se integra. De ellos nos ocupamos en las siguientes líneas.

\subsection{El IMPACTO SOBRE EL PECULIAR SISTEMA DE PROTECCIÓN DE LOS DERECHOS FUNDAMENTALES EN LA UNIÓN.}

5 La bibliografía en esta materia es ingente. En los últimos años se han publicado diversas monografías, de desigual valor, en nuestra doctrina, entre las que destacan, con luz propia, las aportaciones de JM Boccio Vázquez (Comunidades europeas y derechos humanos. Fundación Juan March. Madrid, 1986), A Chueca Sancho (Los derechos fundamentales en la Comunidad Europea. Bosch. Barcelona, 1999); A Salinas de Frías (La protección de los derechos fundamentales en la Unión Europea. Comares. Granada, 2000) y A Rodríguez-Vergara Díaz (Integración europea y derechos fundamentales. Civitas. Madrid, 2001). Unos breves trazos de dicha evolución pueden consultarse en WG II 1, pp. 2 ss.

6 Cfr. «La eficacia de la Carta de Niza», en el libro coordinado por el autor de estas líneas sobre $L a$ protección de los derechos fundamentales en la Unión Europea (Civitas. Madrid, 2002, pp. 123 ss.). 
otro lugar nos hemos ocupado, extensamente, de la gestación, contenido y eficacia de la Carta de Niza, por lo que tales materias no serán, por lo general, retomadas en el presente estudio $^{6}$. Sin embargo, algunos preceptos de la Carta han sido reformulados por el Grupo de Trabajo y la Convención, así como determinadas Explicaciones de la Carta, y tales reformas sí suscitan cuestiones de hondo calado, por lo que merecerán alguna reflexión. Solamente aludiremos a datos históricos en la medida en que los consideremos útiles al objetivo que ahora perseguimos.

Desbrozado así el objeto del presente apartado, podría parecer que el cometido del Grupo II era extremadamente sencillo: pronunciarse acerca de «si la Carta de Derechos Fundamentales debe integrarse en el tratado básico». Sin embargo, a poco que se piense sobre la cuestión planteada, aparecen algunos interrogantes que el Grupo de Trabajo ha debido despejar.

\subsection{Acerca de la incorporación de la Carta a los Tratados.}

El primero se refiere a cómo incorporar la Carta a los Tratados. Sobre esta cuestión ya se pronuncia la nota de reflexión elaborada por la Secretaria (WG II 1, pp. 6 ss., especialmente pp. 7 y 8), que establece seis formas distintas de integración de la Carta:

a) La Carta podría «adjuntarse» a los Tratados en forma de «declaración solemne».

b) Podría incluirse una referencia a la Carta en el Tratado UE o en un nuevo tratado fundamental en la línea del apartado 2 del artículo 6 del actual Tratado UE. Sólo constituiría, pues, una referencia indirecta a la Carta como fuente de inspiración para la definición jurisprudencial de los derechos fundamentales.

c) Podría incluirse una referencia directa a la Carta en el Tratado CE o en un nuevo tratado fundamental.

d) Podría incluirse una referencia directa o indirecta a la Carta en el preámbulo de un nuevo tratado fundamental.

e) La Carta podría convertirse en un nuevo protocolo anejo a los Tratados o a un nuevo tratado fundamental.

f) La totalidad de los 54 artículos de la Carta podría incluirse en un título o capítulo del Tratado UE, o en un nuevo tratado fundamental del que constituiría, por ejemplo, el título primero o el capítulo primero.

Podría parecer que elegir una u otra vía de integración de la Carta en los Tratados es una decisión puramente formal o estética, pero es obvio que el camino elegido repercute en el valor jurídico que se le dé a la Carta. Mientras que la primera opción aumentaría el valor simbólico y político de la Carta, pero sin reforzar su estatuto jurídico actual, la segunda iría algo más lejos, al conferirle relevancia como fuente de inspiración. Sin embargo, las

7 La idea apuntada es actuar en un doble frente. De un lado, se aprobaría la Carta como un Protocolo. De otro, se incluiría una referencia a la Carta en el cuerpo del Tratado. Tal propuesta no deja de ser llamativa, porque, teniendo los Protocolos idéntico alcance jurídico al del Tratado que acompañan, la referencia en los Tratados nada aportaría, desde el punto de vista del Derecho. 
Mientras que algunos miembros defienden la supresión del art. 6.2 TUE en la reunión de 12 de julio de 2002, otros apuestan por su mantenimiento, ya que la Carta no contiene todos los derechos protegidos en el CEDH y el citado precepto favorece «la interpretación de la carta en función de las tradiciones constitucionales comunes» (WG II 7, p. 3). Otros opinan que esta cuestión debe ser debatida después de discutir sobre la adhesión al CEDH (ibídem, p. 4).

Los expertos que han asistido al Grupo tampoco mantienen una posición uniforme en este punto. Mientras que algunos (Piris, Petite) aconsejan el mantenimiento de una referencia a las tradiciones constitucionales comunes, Schoo hace notar que tal decisión aportaría cierta ambigüedad al sistema comunitario de protección de los derechos fundamentales $^{12}$. Por su parte, Vassilios Skouris, magistrado del TJCE, recuerda que las tradiciones constitucionales comunes de los Estados miembros constituyen una fuente de inspiración para la construcción de unos principios generales, que ya no sería preciso mantener si se integra la Carta en los Tratados. Las tradiciones constitucionales comunes se convertirían, a su juicio, en una fuente subsidiaria y complementaria, lo que permitiría al Tribunal recurrir a estas fuentes solamente para colmar posibles lagunas del texto de la Carta (WG II 10, p. 10. Vid, asimismo, p. 7).

Las discrepancias existentes permiten entender que la mayoría de los asistentes a la reunión del Grupo II celebrada el 7 de octubre de 2002 considerara prematuro resolver, con carácter definitivo, acerca de la utilidad de mantener las referencias a las dos fuentes de inspiración que figuran en el art. 6.2 TUE (WG II 15, p. 3), reiterándose las opiniones divergentes en este punto, que ya se hicieron presentes en la sesión celebrada el anterior 12 de julio ( $c f r$., WG II 7).

Pese a todo, el Informe Final del Grupo Carta se pronuncia sobre la materia que ahora nos preocupa, y lo hace por partida doble. Se afirma, en primer lugar, que la interpretación de la Carta debe ser acorde con las tradiciones constitucionales comunes, por lo que la mayoría de los miembros (todos menos dos) propone incluir una norma interpretativa en el art. 52.4 de la Carta, lo que permitiría superar el enfoque del mínimo común denominador en favor de un nivel elevado de protección (W II 16, p. 5). Esta idea se ha plasmado, finalmente, en el art. II-112.4 TECE, en el que se señala que «en la medida en que la presente Carta reconozca derechos fundamentales que tal y como resultan de las tradiciones constitucionales comunes a los Estados miembros, esos derechos se interpretarán en consonancia con dichas tradiciones». La decisión de contemplar esta nueva disposición horizontal o

8 Hemos elegido esta nomenclatura para evitar equívocos con el Tratado de la Comunidad Europea (popularmente conocido como el TCE). Nos valemos de la edición más reciente en el momento de escribir estas líneas, recogida en el documento CIG 87/04, de 6 de agosto de 2004.

9 STJCE Internationale Handersgesellschaft mbH (asunto 11/70), de 17 de diciembre de 1970, Rec. 1970, pp. 1125 ss. Como es sabido, el Tribunal de Luxemburgo, después de una primera etapa en la que se negaba a examinar las quejas referidas a los derechos fundamentales de los recurrentes (época marcada por las SSTJCE Stork \& Cie. vs. Alta Autoridad (asunto 1/58), de 4 de febrero de 1959 (Rec. 1959, pp. 43 ss.); Präsident Ruhrkohlen-Verkaufsgesellschaft y otros vs. Alta Autoridad (asuntos acumulados 36, 37, 38/59 y 40/59), de 15 de julio de 1960 (Rec. 1960, pp. 857 ss.) y Sgarlata y otros vs. Commission CEE (asunto 40/64), de 1 de abril de 1965 (Rec. 1965, pp.279 ss.), cambia de orientación en la trascendental Sentencia Stauder (asunto 29/69), de 12 de noviembre de 1969 (Rec. 1969, p. 419 ss.). El 17 de diciembre de 1970 también dicta el Tribunal de Justicia la Sentencia Einfuhr- und Vorratsstelle für Getreide und Futtermittel vs. Köster (asunto 25/70; Rec. 1970, pp.1161 ss.), en la línea con la reseñada en el texto. 
La adopción de un catálogo de derechos fundamentales en la Unión Europea plantea dos interrogantes relacionados con el modelo comunitario de los derechos que ha venido operando hasta ahora en la Unión Europea.

\subsection{1. ¿Qué hacer con las fuentes de inspiración?}

Como es sabido, muchos de los derechos fundamentales que el Tribunal de Justicia de Luxemburgo ha señalado que forman parte de dicho sistema no están expresamente positivizados en ninguna norma de la Unión Europea. Según la clásica afirmación del Tribunal de Luxemburgo, el «respeto de los derechos fundamentales es parte integrante de los principios generales del Derecho cuya observancia asegura el Tribunal de Justicia» ${ }^{9}$. En la misma resolución se nos dirá que la salvaguarda de estos derechos se inspira en las tradiciones constitucionales comunes a los Estados miembros y, en otra relevante decisión (Sentencia Nold) se realizará otra importante declaración, al señalar que los «instrumentos internacionales relativos a la protección de los derechos del hombre a los cuales los Estados miembros han cooperado o se han adherido, pueden igualmente aportar indicaciones que conviene tener en cuentas $\rangle^{10}$. Desde entonces, el TJCE ha tomado en consideración diversos tratados internacionales en materia de derechos fundamentales, ocupando un claro protagonismo el Convenio Europeo de Derechos Humanos.

El precipitado de toda esta jurisprudencia es el que los Representantes de los Gobiernos de los Estados miembros destilan en el art. F.2 del Tratado firmado el 7 de febrero de Maastricht: «La Unión respetará los derechos fundamentales tal y como se garantizan en el Convenio Europeo para la Protección de los Derechos Humanos y de las Libertades Fundamentales firmado en Roma el 4 de noviembre de 1950, y tal y como resultan de las tradiciones constitucionales comunes a los Estados miembros como principios generales del Derecho comunitario», precepto que habitualmente ha sido interpretado como un mero respaldo a la tarea desempeñada por el Tribunal de Luxemburgo en la protección de los derechos fundamentales de la Unión.

Los debates del Grupo en este punto se han visto condicionados por la Nota de reflexión elaborada por la Secretaría. En la misma se indica que la incorporación de la Carta a los Tratados comunitarios no implica, necesariamente, la supresión de la remisión del art. 6.2 TUE $^{11}$ al CEDH y a las tradiciones constitucionales comunes, ya que «la Carta no impedirá al Tribunal de Justicia seguir inspirándose en estas fuentes adicionales» (WG II 1, p. 9). Sin embargo, a favor de la supresión de estas categorías juega la consideración de que la Carta es la «expresión más auténtica del acervo de derechos fundamentales propios de la Unión Europea» (WG II 1, p. 10).

10 Asunto 4/73, Sentencia de 14 de mayo de 1974, Rec. 1974, p. 491 y ss.

11 Numeración que tiene su origen en el Tratado de Ámsterdam y que se mantiene tras el Tratado de Niza. El contenido del precepto es similar al art. F.2 del Tratado de Maastricht.

12 Estas opiniones fueron valoradas en la reunión del Grupo celebrada el 23 de julio de 2002 (cfr. WII 8, p. 8). Es de justicia reseñar igualmente las reservas expresadas por Petite, al recordar que el Tribunal de Luxemburgo se ha servido de muchas fuentes de inspiración distintas y porque algunos derechos de la Carta aún no están consagrados en todos los Estados miembros —reunión del 23/07/2002 (WG II 8, p. 7)—. 
contemplados en textos extranjeros de igual alcance, sin que hable en tales supuestos de lagunas. Así, por ejemplo, el constituyente español no ha establecido un derecho a la dignidad (como sin embargo reconoce el art. 1 de la Constitución alemana) ni cuenta con un derecho a la vida privada, que tanto juego ha dado en el ordenamiento constitucional francés.

Tampoco es de recibo justificar el mantenimiento del art. 6.2 TUE en el dato, anecdótico por otra parte, de que no se hayan incluido en la Carta algunos derechos recogidos en el CEDH, puesto que, como es obvio, estos últimos son derechos subjetivos, pero no fundamentales, desde el momento en que, por ejemplo, la Unión se adhiera al Convenio. Podría parecer que esta distinción entre derechos fundamentales y derechos humanos es especialmente frágil en la Unión Europea, en la que el Tribunal de Justicia debe controlar el respeto de unos y otros, pero es posible que la misma pueda ser útil en el futuro. Así, por ejemplo, si un día se estableciera un recurso de amparo ante el Tribunal de Luxemburgo, el mismo debería servir, en principio, para garantizar derechos fundamentales de la Unión, pero no para tutelar derechos subjetivos, aunque estos traigan causa del CEDH. Esto es lo que, en opinión del autor de estas líneas, ocurre hoy (o debería ocurrir) en relación con los recursos de amparo que, en el plano nacional, se prevén en determinadas Constituciones. Por poner un ejemplo, así como el Tribunal Constitucional español no puede proteger, a través del amparo constitucional, el derecho de propiedad (por no contar con tal garantía jurisdiccional suplementaria ex art. 53.2 CE) o el derecho a la vida privada o a la dignidad (por no ser, en puridad, derechos fundamentales en el ordenamiento constitucional español), resulta claro que la Administración y los tribunales (ordinarios) están llamados a respetar la vida privada de los justiciables porque así lo impone el art. 8 CEDH.

El mantenimiento del art. 6.2 TUE resulta perturbador, en definitiva, porque introduce inseguridad allí donde no debiera haberla (el listado de los derechos fundamentales) y genera problemas de interpretación cuando hace referencia a dos realidades de distinta naturaleza (un catálogo concreto, el CEDH, que ha sido interpretado de forma auténtica por el Tribunal de Estrasburgo, y otra categoría inaprensible, las tradiciones constitucionales comunes, cuya concreción en un determinado caso exige y permite mayores esfuerzos interpretativos, y, por ende, mayor margen de actuación al Tribunal de Luxemburgo).

La conclusión de todo este razonamiento es que estimamos, a diferencia de lo señalado en Informe final del Grupo II, que la referencia contenida en el art. 6.2 TUE sí debe quedar excluida del Tratado si se confiere a la Carta realce vinculante. En el mismo lugar se señala, como ya hemos adelantado, que dicha referencia debería ser adecuada. Y si se examina el art. I-9.3 TECE desde esta perspectiva, es obligado hacer notar que el texto finalmente propuesto no se ajusta a las expectativas del Grupo II.

Como ya hemos adelantado, este precepto señala que «Los derechos fundamentales que garantiza el Convenio europeo para la protección de los derechos humanos y de las libertades fundamentales y los que son fruto de las tradiciones constitucionales comunes a los Estados miembros forman parte del Derecho de la Unión como principios generales». Dejando de lado la incorrección técnica de entender que los derechos contenidos en un texto internacional son derechos fundamentales, parece que el art. I-9.3 TECE puede ser entendido como un compromiso unilateral por parte de la Unión de respetar todos los derechos recogidos en la doble fuente de inspiración, extremo que no se colige, necesaria- 
general es criticable, porque el tratamiento del CEDH y de las tradiciones constitucionales comunes, pese a lo sugerido por algunos miembros del Grupo II, no debe ser considerado idéntico o similar. De un lado, por su distinta naturaleza (escrita y principial, respectivamente) y, de otro, porque ambos crean obligaciones jurídicas distintas, sobre todo si la Unión se adhiere al CEDH.

El Informe Final opta, en segundo lugar, por el mantenimiento de la referencia a las fuentes externas (como las que figuran actualmente en el apartado 2 del art. 6 TUE). Aunque algunos sostienen que la mención de tales fuentes de inspiración en el art. 6.2 TUE sería redundante y crearía confusión jurídica, otros argumentan que tal referencia permite completar la protección ofrecida por la Carta y precisar que el Derecho de la Unión está abierto a la evolución futura del CEDH y de la legislación de los Estados miembros en materia de derechos humanos (W II 16, p. 9). En todo caso, concluye el Informe Final, la referencia a tales fuentes externas — siempre que sea adecuada y que la Convención debe decidir-, no queda excluida, a juicio del Grupo II, por la perspectiva de una Carta jurídicamente vinculante (W II 16, p. 10).

La Convención ha optado, finalmente, por incluir en el Proyecto de Tratado una versión distinta del vigente art. 6.2 TUE, que ahora reza, bajo el numeral I-9.3, «Los derechos fundamentales que garantiza el Convenio europeo para la protección de los derechos humanos y de las libertades fundamentales y los que son fruto de las tradiciones constitucionales comunes a los Estados miembros forman parte del Derecho de la Unión como principios generales».

Aunque los argumentos esgrimidos por el Grupo II han sido convincentes (en la medida en que no se han visto alterados ni por la Convención ni por la Conferencia de los Representantes de los Gobiernos de los Estados Miembros), no son inatacables. La decisión de mantener una referencia al CEDH y a las tradiciones constitucionales comunes en el art. I-9.3 TECE es discutible desde el momento en que se articula un listado exhaustivo de derechos fundamentales, sin que sean convincentes los argumentos que justifican tal decisión.

Así, por ejemplo, la idea de que la Carta no retoma todos los derechos recogidos en el CEDH o que puede presentar lagunas no es excesivamente afortunada. A este alegato podría responderse, desde una perspectiva general, que todo catálogo de derechos fundamentales es, por esencia, limitado (esta idea viene impuesta por su propia naturaleza jurídica), siendo imposible una extensión ilimitada de derechos fundamentales, y que, además, la Carta elaborada en la Unión puede tener muchos defectos, pero entre ellos no figura, a todas luces, la de que sea un texto minimalista o parco en el reconocimiento de los derechos efectivamente contemplados.

Pero, yendo más en particular a las ideas expresadas, es conveniente señalar que, en puridad, no debería hablarse de lagunas, sino de inexistencia de derechos fundamentales. Si pudiera pensarse en algún derecho que no aparece contenido en la Carta, lo lógico sería pensar que no se trata de una laguna, sino que ese derecho, como tal, no ha sido incluido entre los derechos fundamentales de la Unión. Tal conclusión es la que, desde una perspectiva lógica, debe imponerse, sin que pueda pensarse que cualquier derecho reconocido como relevante en cualquier texto, ya sea de naturaleza constitucional o internacional, debe reputarse como fundamental en el seno de la Unión Europea. Basta examinar cualquier texto constitucional para apreciar que no recoge derechos fundamentales que sí aparecen 
En efecto, en la sesión del Grupo II celebrada el 23 de julio de 2002 se parte de la premisa de que las duplicaciones pueden ser contempladas desde dos perspectivas distintas. Desde una primera, centrada en el principio de seguridad jurídica, se propone el mantenimiento de las duplicidades y, muy especialmente, del art. $52.2 \mathrm{CN}^{14}$. Sin embargo, quienes defienden la mayor inteligibilidad del nuevo Tratado aconsejan eliminar tales duplicidades (WG II 8, p. 2).

El primer argumento carece, a nuestro juicio, de la más mínima consistencia, puesto que una doble regulación de un mismo derecho en el mismo Tratado no favorece, a primera vista, el principio de seguridad jurídica. Lo lógico habría sido, a todas luces, desplazar las restantes disposiciones del Tratado referidas a derechos fundamentales al articulado de la Carta, lo que hubiera permitido — acaso $^{15}$ — la desaparición del art. 52.2 CN y hubiera servido para presentar una regulación conjunta de los derechos fundamentales de la Unión, lo que alguna relevancia tiene si se pretende hacer más visible para el ciudadano. Pese a su manifiesto desacierto, la idea de que la correcta coordinación entre los derechos de la Carta y los recogidos en otras partes del Tratado reposa en el art. 52.2 CN pronto se abre paso, aunque igualmente pronto se empiece a hablar de su eventual reforma (WG II 8, p. 2).

Puede decirse, a modo de resumen, que se ve con agrado la aceptación de duplicaciones entre la Carta y el actual TCE, puesto que algunos derechos (libertades comunitarias) son regulados con mayor detalle en los Tratados (ibídem, p. 3). La única voz discrepante en este punto es la aportada por Piris, que propone retomar en la $\mathrm{CN}$ todas las condiciones y límites que figuran en el Tratado, o que, al menos, se hagan referencias directas a los preceptos de éste (ibídem, p. 4). Sin embargo, esta tesis pierde fuerza en el Grupo, que opta por seguir la opinión de Petite, de que solamente sería preciso adaptar el art. 52.2 CN.

No es de extrañar que el Informe Final del Grupo II defienda la plena compatibilidad entre los derechos fundamentales recogidos en el Tratado de la Comunidad Europea y los artículos de la Carta que los reafirman. La primera Convención entendió que la Carta no debería afectar a la situación jurídica definida por aquél, y es posible entender que una reglamentación más detallada se contenga, a partir de la incorporación de la Carta en los Tratados, en otras partes de los mismos. En definitiva, una cláusula de remisión entre unas y otras disposiciones justificaría su plena compatibilidad (WG II 16, p. 6). Los argumentos utilizados son, una vez más, desafortunados. Es evidente que la primera Convención estaba vinculada por los Tratados porque su único encargo era hacer un documento que contuviera el listado de los derechos fundamentales. Muy distinta es la tarea que debe desempeñar la Convención en el marco de la CIG'2004, porque está elaborando un proyecto de Tratado, por lo que éste le es enteramente disponible, en principio.

La única excepción que se hace en el citado Informe evidencia la debilidad de la argumentación del Grupo en este punto. La única eventual refundición que se plantea, a modo de hipótesis, es la referida a los derechos vinculados con la ciudadanía de la Unión, y que no trae causa de una decisión material (relevancia política de aquélla), sino de algo tan circunstancial como que la Carta formara parte de la primera parte del Tratado. Solamente en ese supuesto sería necesario, a juicio del Grupo, combinar en dicho Tratado los artículos de la Carta relativos a los derechos de los ciudadanos y las disposiciones sobre ciudadanía

$13 \mathrm{El}$ aserto se explica por la matización que el propio Tribunal de Justicia realiza en la ya citada Sentencia Internationale Handersgesellschaft $\mathrm{mbH}$, al que aludiremos infra. 
mente, de la jurisprudencia comunitaria en la materia, en la que se afirma que los derechos fundamentales de la Unión, que son los recogidos en los principios generales del Derecho comunitario, se interpretarán de conformidad con las precitadas fuentes de inspiración.

Si esta interpretación no es infundada, se observa un salto entre la doctrina del Tribunal de Justicia y la nueva previsión contenida en los Tratados. En efecto, siguiendo aquélla, el Tribunal de Justicia de las Comunidades Europeas es el órgano encargado de decidir cuáles son los derechos fundamentales de la Unión (nomen) recogidos en los principios generales del Derecho comunitario, señalando que su alcance (contenido) será determinado, en principio ${ }^{13}$, a la vista de las fuentes de inspiración a las que ya se ha hecho reiterada referencia. Salvando las distancias, esta formulación sería equivalente a la que juega, en el Derecho constitucional español, el art. 10.2 CE. Si bien es la Constitución (y solamente la Constitución), la que determina cuáles son los derechos fundamentales, se indica en el citado precepto que las normas existentes en tales materias se interpretarán de conformidad con los tratados y acuerdos internacionales ratificados por España. Sin embargo, y como ya se ha adelantado, el artículo I-9.3 TECE permite colegir que los derechos contenidos en el CEDH son, también, derechos subjetivos contenidos en el Derecho comunitario, que las Instituciones y órganos de la Unión se comprometen a respetar.

\subsection{2. ¿Qué hacer con los derechos que ya aparecen recogidos en otras disposiciones de los Tratados comunitarios? El problema de las duplicaciones.}

Hemos señalado que los Tratados originarios no incluían, como tal, un catálogo de derechos fundamentales. Sin embargo, desde un primer momento, reconocían determinados derechos subjetivos que las Instituciones debían asegurar. Clásicas son, por ejemplo, las referencias a las libertades comunitarias (libre circulación de trabajadores, mercancías, servicios y capitales) y a determinados derechos laborales (no discriminación por razón de sexo). Con el tiempo, tales referencia se han ido acrecentando (muy especialmente, con el Tratado de Maastricht que regula una serie de derechos vinculados a la idea de la ciudadanía de la Unión).

La incorporación de la Carta de Niza a los Tratados exige decidir que hacer con las referencias ya contenidas en los Tratados. Ya en la nota de reflexión elaborada por la Secretaria se identifican, como preceptos duplicados, los referidos a la libre circulación, casi todos los derechos del capítulo de ciudadanía y las cláusulas de no discriminación por razón de nacionalidad y de igualdad entre ambos sexos, por lo que se plantea, como tema de debate, si es posible suprimir tales reiteraciones y, en su caso, si la supresión debiera producirse en los preceptos del Tratado incluidos en la Carta o fuera de ella (WG II 1, p. 11).

El sentido común, y una de las cuestiones sobre las que la Convención debía pronunciarse (la simplificación de los Tratados), parece aconsejar, a priori, suprimir tales duplicidades en el texto del Tratado. Sin embargo, la decisión adoptada no ha tomado en consideración el citado argumento, sino que el debate ha girado en torno a otras consideraciones.

14 Precepto que disponía que «Los derechos reconocidos por la presente Carta que tienen su fundamento en los Tratados comunitarios o en el Tratado de la Unión Europea se ejercerán en las condiciones y dentro de los límites determinados por éstos». 
Preámbulo de la $\mathrm{CN}$ y de las Explicaciones que en su día elaboró la primera Convención. Estas cuestiones serán examinadas en las siguientes líneas, que se centrarán, posteriormente, en el análisis de la eficacia de la Parte II TECE.

\section{EL CONTENIDO DE LA CARTA Y DE LAS EXPLICACIONES TRAS LA CIG'2004.}

En líneas anteriores ya hemos adelantado que, aunque la intención inicial del grupo partía del respeto al trabajo realizado por los autores de la $\mathrm{CN}$, se veía preciso realizar algunas modificaciones puramente técnicas. Sin embargo, desde el primer momento pareció que las disposiciones horizontales que formaban parta de la $\mathrm{CN}$ precisaban ciertos ajustes. Este empeño podría haberse justificado, sin mayores esfuerzos intelectuales, en los reproches doctrinales que las mismas habían provocado. Este dato, unido a la evidente importancia que presentan ${ }^{19}$, explica que hayan sido modificadas. Interesa determinar en qué sentido se han producido tales reformas y evaluar su acierto.

El Presidente del Grupo, António Vitorino, se comprometió, en la sesión del Grupo II celebrada el 12 de julio de 2002, a presentar un documento sobre la eventual modificación de los arts. 51.2 y $52.2 \mathrm{CN}$, así como de las derivadas de las duplicaciones (WG II 7, p. 5). La necesidad de estas adaptaciones ${ }^{20}$ se reitera en la reunión de 23/07/2002, y poco más tarde se llega a un consenso casi global acerca de que se recomendarán ligeras adaptaciones de ciertas disposiciones horizontales $\mathrm{CN}^{21}$. El Presidente presentó sus propuestas transaccionales en la materia el posterior 4 de octubre (WG II WD 023), iniciativa que mereció el elogio de una amplia mayoría de los participantes de la reunión del Grupo II celebrada el 7 de octubre de 2002. Se insiste, en el acta de dicha sesión, en que tales modificaciones no suponen un cambio de fondo de la Carta y que, sin embargo, contribuirían para convencer a los Gobiernos y a los parlamentos nacionales de la conveniencia de que se integrara la CN en los Tratados (WG II 15, p. 2). Esta última afirmación permite sospechar que acaso no estemos, como se pretende, ante meros ajustes técnicos.

Lo cierto es que un miembro del Grupo se declaró contrario a las propuestas de adaptación realizadas, por no respetar el método de trabajo, por su escasa utilidad y porque algunas de ellas no son, a su juicio, dignas de un texto constitucional. Afirma, además, que no era una de las misiones que el Grupo debía realizar, de lo que discrepa el Presidente del Grupo (WG II 15, p. 2). Finalmente, se muestran conforme con una versión ligeramente modificada de las adaptaciones de los arts. 51 y 52 de la Carta y sobre ciertos elementos explicativos de las mismas que se incluirían en el informe, actualizando también las explicaciones (ibídem, p. 3).

De ahí que el Informe Final del Grupo II sugiera que se introduzcan en las disposiciones horizontales «ajustes técnicos de redacción» ${ }^{22}$ que servirían para «confirmar», aclarar

15 Esta cuestión depende, claro está, del alcance que se le confiera al término «Tratados comunitarios». Aunque el tenor literal admite pocas interpretaciones extensivas, ésta ha sido la óptica manejada por los distintos expertos que han asesorado al Grupo II. Piris, Petite y Schooo entienden que la referencia a los Tratados alcanza igualmente al Derecho comunitario derivado — reunión del 23/07/2002 (WG II 8, p. 8)—. Los derechos regulados en el Tratado CE son lex specialis respecto de los contenidos en la carta, por lo que los mismos y la jurisprudencia existente relativa a esos derechos se mantendría en vigor, a juicio de Vassilios Skouris, Juez del TJCE (WG II 10, p. 10). 
del Tratado CE que tienen importancia constitucional ${ }^{16}$. Que, a juicio del Grupo esto no seria lo más deseable, es que enseguida se justifique tal decisión, afirmando que tal operación debería entenderse como puramente técnica y no plantea, por ello mismo, problemas políticos (WG II 16, p. 6). Quizás esta afirmación explique que la Carta finalmente aprobada figure como segunda parte del Tratado que ya se ha sometido a las autoridades nacionales.

Nuestras reservas sobre la doble regulación contenida en los Tratados no se agota en motivos de mera técnica jurídica, aunque estos sean relevantes. No es deseable, con carácter general, que una misma materia sea regulada en dos preceptos distintos y no cercanos de una misma norma. Pero dicho esto, es posible plantearse, además, si es verdad que la aprobación de los preceptos de la Carta no modifican el alcance de los preceptos anteriormente recogidos en los Tratados. Solamente podría negarse tal aporte jurídico en el supuesto de que se le negara carácter jurídico a los preceptos de la Carta que reiteran otros artículos de los Tratados, lo que parece difícil de construir. Lo que queremos afirmar es que, si como opina Vassilios Skouris, los derechos regulados fuera de la Carta son lex specialis respecto de los que allí se incluyen, no es descartable que la interpretación de aquellos pueda verse afectada por éstos. Esto puede ocurrir, por ejemplo, con la difícil relación que están llamados a tener, en el futuro, los arts. 13.1 TCE (cfr. III-124 TECE), que prevé que el Consejo de Ministros pueda adoptar acciones adecuadas para luchar contra la discriminación, y el art. 21 de la Carta (II-81 TECE), que la prohíbe en el marco de la Unión. Aunque pueda sostenerse, atendiendo al diferente tenor de uno y otro precepto, que estos presentan una naturaleza y alcance distintos ${ }^{17}$, es obvio que una ordenación inteligible del Tratado patrocinaba su regulación conjunta.

Es igualmente cierto que la introducción de la Carta en los Tratados comunitarios exigía modificar todas las llamadas que aquélla hacía a estos. Tales reformas no planteaban problema alguno (se trataba, en principio, de cambiar las referencias hechas «a los Tratados» aludiendo ahora «a las otras partes del Tratado»). Sin embargo, el Grupo de Trabajo II ha ido más lejos en esta tarea, modificando, en primer lugar, determinadas disposiciones horizontales (llamadas en el nuevo TECE generales ${ }^{18}$ ), y preocupándose por el futuro del

16 En la reunión del 23 de julio de 2002 se había sugerido que, mientras que en la primera parte del Tratado se podría integrar la definición de la ciudadanía y una disposición sobre el futuro desarrollo de ésta (cfr. Arts. 17 y 22), en la segunda parte se contendrían los derechos del ciudadano (WG II 8, p. 3).

17 Se discute desde el primer momento si se puede considerar que el art. $21 \mathrm{CN}$ altera el art. $13 \mathrm{TCE}$, pero ya en aquél momento se señala que estas disposiciones son de naturaleza y alcance distintos. Mientras que el art. 13 TCE constituye una base jurídica para dictar normas aplicables entre particulares; el art. 21.1 CN recoge un derecho subjetivo frente a las instituciones y órganos de la UE y a los Estados miembros cuando aplican Derecho de la UE (WG II 1, p. 13, y nota 1). No deja de ser significativo que un miembro del Grupo, Bobby Mcdonagh, proponga la introducción de un párrafo en las Explicaciones al hilo del art. $21 \mathrm{CN}$ en el que la distinto alcance de ambos preceptos se exteriorice (WG II WD 28, p. 13). Tal pretensión se ha visto satisfecha si se compara el texto de las Explicaciones de la Carta presentado por el Presidente del Grupo II, António Vitorino (WG II WD 27) y el finalmente aprobado (CONV 828/1/03 REV 1, de 18 de julio de 2003), en el que puede leerse ahora que «No existe contradicción o incompatibilidad entre el apartado 1 y el artículo [III-8] de la Constitución, que tiene objetivos y alcance diferentes: el artículo [III-8] confiere competencias a la Unión para adoptar actos legislativos, incluida la armonización de las disposiciones legales y reglamentarias de los Estados miembros, con el fin de combatir determinadas formas de discriminación que se especifican de forma exhaustiva en el citado artículo. Dicha legislación podría cubrir la acción de las autoridades de los Estados miembros (así como las relaciones entre personas privadas) en cualquier ámbito dentro de los límites de las competencias de la Unión. Las disposiciones del apartado 1 no confieren, sin embargo, competencias para promulgar actos legislativos con el fin de 
vas para la Unión y no modifica las competencias y misiones definidas en las demás partes de la Constitución.

Si bien es cierto que no todo el mundo es partidario de reformar el art. $51.1 \mathrm{CN}^{26}$, sí que se ha dicho una y otra vez que la Carta no alteraba el reparto competencial existente entre la Unión y los Estados miembros ${ }^{27}$. Los expertos están divididos en este punto. Mientras que el Sr. Piris sostiene que sería recomendable modificar el art. 51.1 (que habla de promover...), para aclarar que la integración de la Carta no confiere nuevas competencias a la Unión, los señores Schooo y Petite creen que tal reforma no sería necesaria, aunque sí una adaptación técnica del art. 51.2 CN si se integra la Carta a través de su inclusión en el Tratado (WG II 8, p. 4). Por su parte, el Juez del Tribunal de Justicia de la CE (TJCE) Vassilios Skouris estima que la integración de la Carta no podría modificar el reparto de competencias entre la Unión y los Estados miembros si se adaptan convenientemente los arts. 51.2 y 52.2 de la Carta $^{28}$.

A la vista de estos datos no es de extrañar que, en el Informe Final del Grupo II, se afirme que la incorporación de la Carta no modificará el reparto de competencias entre la Unión y los Estados miembros (WG II 16, p. 5). Se recomienda, en todo caso, la realización de ciertas modificaciones de los arts. 51.2 y $51.2 \mathrm{CN}$, así como reiterar el respeto del principio de subsidiariedad ${ }^{29}$. Esta última pretensión se articula, en lo que ahora interesa examinar $^{30}$, en un nuevo artículo: el II-112.6 TECE. En el mismo se señala que «se tendrán plenamente en cuenta las legislaciones y prácticas nacionales según lo especificado en la presente Carta».

El lacónico texto que explica este precepto (que se dice «remite a los diferentes artículos de la Carta que, en aras de la subsidiariedad, hacen referencia a la legislación y prácticas nacionales $»^{31}$ ) no resuelve todas las dudas interpretativas que plantea. La principal, de la que queremos dejar expresa constancia en este estudio, es que admite un mal encaje la alusión de las prácticas nacionales con la invocación de un contenido esencial de los derechos fundamentales (art. II-112.1 TECE) y con la obligación de los Estados de respetarlos cuando apliquen el Derecho de la Unión (art. II-111.1 TECE), salvo que se pretenda aludir al denominado contenido suplementario de los derechos fundamentales, materia ésta que siempre es sensible desde la perspectiva del principio de igualdad.

combatir formas de discriminación en ámbitos de acción de los Estados miembros o en la esfera privada, ni constituyen una prohibición generalizada de la discriminación en ámbitos tan amplios. Se refieren solamente a las discriminaciones por parte de las instituciones y organismos de la Unión en el ejercicio de las competencias conferidas con arreglo a otros artículos de las partes I y III de la Constitución, y por parte de los Estados miembros cuando apliquen el Derecho de la Unión solamente. Por consiguiente, el apartado 1 no modifica el alcance de las competencias conferidas con arreglo al artículo [III-8] ni la interpretación de dicho artículo» (p. 24).

18 Ya hemos hecho referencia, supra, al nuevo art. II-112-4 TECE.

19 Piris, Petite y Schooo subrayan la relevancia de las disposiciones horizontales (cfr. WG II 8, p. 6).

20 Idea que se reitera en la reunión celebrada el 23 de julio de 2002 (WG II 8, p. 1).

21 Consenso de que se da cuenta en la nota de síntesis de la sesión del Grupo realizada el 17 de septiembre de 2002 (WG II 10, p. 7). 
y reforzar desde el punto de vista jurídico determinados elementos clave del consenso global logrados por la anterior Convención respecto de la Carta. Tales modificaciones se explican por la nueva perspectiva de un Tratado constitucional y por motivos de seguridad jurídica en el ámbito de los derechos fundamentales ${ }^{23}$.

Es oportuno hacer notar que las previsiones contenidas en el art. $52 \mathrm{CN}$, referidas a la idea del desarrollo legal de los límites de los derechos (52.1), a la relación que mantienen con los derechos recogidos en otras partes del Tratado (52.2) y de los que corresponden con los derechos garantizados en el CEDH (52.3), aunque presentan evidentes flancos a la crítica, se han mantenido inalterables (arts. II-112, apartados 1, 2 y 3, TECE), por lo que no nos ocuparemos de ellos en el presente estudio ${ }^{24}$.

\subsection{SOBRE EL CONTENIDO DE LA CARTA.}

\subsubsection{La dimensión negativa: la Carta no recoge nuevas competencias en favor de la Unión.}

Si se examina el art. II-111.1 TECE se observará que se ha añadido una coletilla final al viejo art. $51.1 \mathrm{CN}$, en la que se dispone que las Instituciones, los órganos y los organismos de la Unión respetarán los derechos, observarán los principios y promoverán su aplicación, con arreglo a sus respectivas competencias y «dentro de los límites de las competencias que se confieren a la Unión en las demás Partes de la Constitución». Se retoma así el contenido que antes se encontraba recogido en el art. $51.2 \mathrm{CN}^{25}$, que, de forma obsesiva, ha marcado los debates del Grupo.

Aunque esta addenda habría permitido excluir la reserva hasta el momento contenida en el art. 51.2 CN, el Grupo de Trabajo no solamente no ha optado por tal dirección, sino que ha tratado de delimitar con mayor precisión, los efectos de la plena incorporación de la Carta al Tratado. Se afirma así, en el art. II-111.2 TECE, que «La presente Carta no [sic] amplía el ámbito de aplicación del Derecho de la Unión más allá de las competencias de la Unión» ni crea ninguna competencia ni ninguna misión nue-

22 Además de evidentes correcciones en relación con los términos Tratados, los tratados comunitarios, etc.. W II 16, p. 4, nota 1. 17).

23 WG II 16, p. 4. El texto de las modificaciones propuestas se recoge en un Anexo adjunto (ibídem, p.

24 Ya lo hemos hecho en «La eficacia...». Sí que nos interesa subrayar en el contexto del presente estudio que algunos se han planteado la eventual reforma de alguno de estos preceptos. Se ha cuestionado, por ejemplo, si era compatible la plena integración de la $\mathrm{CN}$ en el Tratado con el mantenimiento del art. 52.2 CN. El propio Informe inicial de la Secretaria se cuestiona, en idéntica dirección, si es conveniente que se señale en cada uno de los arts. de la $\mathrm{CN}$ que recogen derechos contemplados en otra parte de los Tratados, que estos se ejercerán en las condiciones y dentro de los límites previstos en aquellos, para conjurar la inseguridad jurídica (WG II 1, p. 12).

Sin embargo, los debates más interesantes se han producido en relación con el art. $52.3 \mathrm{CN}$. Este precepto es considerado ambiguo por Piris, porque es el Tribunal de Luxemburgo quien debe determinar si son, o no, aplicables los límites del CEDH. Discrepan de este parecer Petite y Schoo, considerando suficiente la referencia contenida a «su sentido y alcance» - reunión de 23/07/2002 (WII 8, p. 6)-. El Juez Marc Fischbach, del TEDH, se muestra satisfecho con este artículo, que entiende suficientemente claro, aunque su aplicación pueda ser problemática si se pretende una cierta armonización en materia de derechos humanos, sobre todo cuando la UE actúa en materias sensibles, como es el tercer pilar (WG II 10, p. 4). Aunque en el seno de la reunión celebrada 


\subsection{Sobre El PREÁmbUlo y las ExPlicaCiOnes QUE ACOMPAÑAN A LA CARTA.}

Se ha afirmado, en líneas anteriores, que es probable que una de las razones que explica que la Carta integre la segunda parte del Tratado era que no se viesen alteradas las disposiciones duplicadas referidas a la ciudadanía europea. Si hay algún otro motivo que justifique esta decisión es la férrea voluntad del Grupo II de preservar el preámbulo que en su día acompañó a la $\mathrm{CN}$.

El Grupo considera, en efecto, en su Informe Final, que el preámbulo de la Carta es un elemento crucial del consenso global sobre la Carta alcanzado en la Convención anterior, por lo que debe recogerse, ya sea como preámbulo del Tratado o de la parte del Tratado o Protocolo correspondiente (WG II 16, p. 9). Aunque este entendimiento contrasta con la afirmación de que el preámbulo del Tratado presenta escaso valor jurídico (WG II 1, p. 8), el objetivo del Grupo II se ha visto logrado, desde el momento en que se ha recogido el antiguo Preámbulo de la $\mathrm{CN}$ en el que abre, ahora, la Parte II del Tratado.

La única variación que se ha producido en el mismo ha traído causa de la Reunión de los Jefes de Estado o de Gobierno celebrada en Bruselas los días 17 y 18 de junio de 2004, y que ha consistido en señalar que las Explicaciones elaboradas bajo la autoridad del Praesidium de la Convención que elaboró la Carta han sido actualizadas bajo la responsabilidad del Praesidium de la Convención Europea (CIG 84/04 PRESID 26, de 18 de junio, p. 17).

Esta y otras iniciativas políticas de los Jefes de Estado o de Gobierno, que han consagrado ciertas adiciones en el TECE, hacen referencia directa a las mentadas Explicaciones. De un lado, en la mentada reunión se aprueba una Declaración sobre las explicaciones relativas a la Carta de los Derechos Fundamentales que deberá constar en el Acta Final, para dejar constancia de que la Conferencia toma nota de su existencia y actualización. De otro, y ésta es la principal novedad, se incluye un nuevo art. II-112.7 TECE, en el que se indica que «Las explicaciones elaboradas como medio de dar orientación en la interpretación de la Carta de los Derechos Fundamentales serán tenidas debidamente en cuenta por los tribunales de la Unión y de los Estados miembros» (ídem). Se reproduce así, casi en términos literales, una afirmación ya vertida en el preámbulo de la Explicaciones elaboradas por el Praesidium de la Convención Europea (CONV 828/1/03 REV 1, de 18 de julio de 2003, p. 4), pero que ahora goza, por su privilegiada posición en el Tratado, de un indiscutible carácter vinculante.

el 17 de septiembre de 2002 se solicitó que la Presidencia clarificara el sentido que debe darse al art. 52.3 CN y la relación que guarda la primera frase con la segunda (WG II 10, p. 7), tal petición no se ha concretado en ninguna alteración del citado precepto (actual II-112.3 TECE). El Informe Final del Grupo señala, en este punto, que la correspondencia entre los derechos de la Carta y los derechos garantizados por el CEDH, asegurada por el art. 52.3 CDFUE, no se opone a una protección más extensa por la legislación europea o por algunos artículos del TECE (WG II 16, p. 7).

25 «La presente Carta no crea ninguna competencia ni ninguna misión nueva para la Comunidad ni para la Unión y no modifica las competencias y misiones definidas por los Tratados».

26 Cfr. WG II 8, p. 2, que da cuenta de la reunión celebrada el 23 de julio de 2002.

27 Vid, por ejemplo, la nota que resume la sesión del 12 de julio de 2002 (WG II 7, p. 4). 


\subsubsection{La dimensión positiva: derechos y principios.}

Piris señala que algunas disposiciones de la Carta carecen de la precisión necesaria, ya que no se aclara si son derechos, libertades o principios ( $c f r$. WG II 8, p. 7). Este dato no seria excesivamente relevante a menos que hubiera un régimen jurídico diferenciado para cada una de estas categorías. El Preámbulo de la CN se limitaba a señalar que la Unión reconoce los «derechos, libertades y principios» enunciados a continuación. Por su parte, el art. 51.1 CN señalaba que las Instituciones, órganos y organismos de la Unión respetarían los derechos, observarían los principios y promoverían su aplicación. De este precepto, el único matiz que podría diferenciar los derechos y los principios es que, aun cuando todos ellos deben ser respetados, los principios pueden ser además promovidos.

Algunos miembros del Grupo II sugieren, sin embargo, que se ahonde en la distinción que figura en la Carta entre derechos y principios (WG II 10, p. 7), aunque el señor Skouris opina que la delimitación entre derechos y principios puede dejarse en manos del propio Tribunal de Justicia (ibídem, p. 8).

Finalmente, el Grupo II decide, en su Informe Final, que se incluya una nueva disposición horizontal en esta materia, sobre la que dos miembros expresan sus reservas, y que dará lugar al. II-112.5 TECE (WG II 16, p. 8), que dispone que «Las disposiciones de la presente Carta que contengan principios podrán aplicarse mediante actos legislativos y ejecutivos adoptados por las instituciones, órganos y organismos de la Unión, y por actos de los Estados miembros cuando apliquen el Derecho de la Unión, en el ejercicio de sus competencias respectivas. Sólo podrán alegarse ante un órgano jurisdiccional en lo que se refiere a la interpretación y control de la legalidad de dichos actos».

Estamos en presencia de una de las mayores novedades que presenta la nueva Carta, pese a que se afirme en el Informe Final que no se trata de nada más que de condensar la interpretación del concepto «principios» que marcó los trabajos de la Convención anterior ${ }^{32}$, puesto que la nueva disposición general ha realizado una lectura diferente de los principios. En primer lugar, porque de la obligación de observar los principios se pasa a la posibilidad de implementarlos (podrán...), lo que constituye un salto en su virtualidad jurídica. En segundo lugar, porque se impide que tales principios puedan ser directamente invocados, negándoseles toda eficacia directa en tanto que derechos. De esta forma se escoge una técnica bien conocida en el Derecho español, que es la referida a los principios rectores de la política social y económica, lo que devalúa el sentido dado a los principios en la $\mathrm{Carta}^{33}$. No estamos, pues, ante un «ajuste técnico», sino ante una carga de profundidad que debilita una buena parte de los contenidos de la Carta.

28 WG II 10, p. 8. La reforma del art. 51.2 CN pretende conjurar que tal extensión competencial de la Unión pueda producirse, si quiera, por inadvertencia (vid., ahora, WG II 8, p. 2), por lo que se aplaude la propuesta de reforma del art. 51.2 contenida en WG II WD 9.

29 Ídem. Se recuerda la referencia contenida en el preámbulo $\mathrm{CN}$ al mentado principio de subsidiariedad.

30 Vid. infra, sobre la vigencia efectiva de los derechos fundamentales en la Unión.

31 Vid. las explicaciones actualizadas sobre el texto de la Carta de los Derechos Fundamentales (CONV 828/1/03 REV 1, 18/07/2003, p. 52). 
Luxemburgo tiene para controlar las actuaciones realizadas al amparo del Título VI TUE, en Asuntos de Interior y Justicia, y que han sido delimitadas por el art. 35 TUE. El Grupo II recuerda que este precepto «ha llevado, por lo que respecta al procedimiento prejudicial del tercer pilar, a un régimen de geometría variable enormemente complejo. El apartado 5 del artículo 35 TUE excluye totalmente la competencia del Tribunal de Justicia, de forma general, para controlar, dentro del tercer pilar, las medidas nacionales policiales o de orden público. Una exclusión análoga está prevista, en virtud del apartado 2 del artículo 68 del Tratado, aun en el pilar comunitario, y para las actuaciones de las instituciones contra las que los jueces nacionales no pueden ofrecer protección alguna. Por último, la limitación del derecho a remitir una cuestión prejudicial que contiene el apartado 1 del artículo 68 del Tratado CE parece de difícil justificación, ya que obliga a los interesados a recorrer todas las instancias nacionales antes de llegar al juez comunitario» (WG II 1, p. 14, que remite al documento CONV 69/02). Se insiste en lo obvio: la relevancia de las materias afectadas desde la perspectiva de los derechos fundamentales (ibídem, p. 15).

En este punto se ha producido un cierto avance en la materia, que se concreta en los nuevos arts. III-376 y III-377 TECE. Aunque en el primero de ellos se sigue afirmando que el Tribunal de Justicia de la Unión Europea no es competente para pronunciarse respecto de las disposiciones particulares relativas a la ejecución de (a) la política exterior y de seguridad común (art. I-40 TECE) y de (b) la política común de seguridad y defensa (art. I-41 TECE), ni de las previstas en el art. III-293 TECE cuando se refieran a la política exterior y de seguridad común, se establece su competencia, en lo que aquí interesa, para pronunciarse sobre los recursos interpuestos en las condiciones previstas en el art. III-365 TECE y «relativos al control de la legalidad de las decisiones europeas por las que se establecen medidas restrictivas frente a personas físicas o jurídicas adoptadas por el Consejo» en las referidas políticas y también en la atinente a la realización del espacio de libertad, seguridad y justicia (art. I-42 TECE) ${ }^{36}$.

32 Cfr. WG II 16, p. 8, que encontrará directo reflejo en la Explicación del art. 52-5 CN.

33 Esta misma impresión produce la lectura de la Explicación que acompaña el texto reseñado en el texto: El apartado 5 aclara la distinción entre «derechos» y «principios» reconocidos en la Carta. Según esta distinción, los derechos subjetivos deberán respetarse, mientras que los principios deben observarse (apartado 1 del artículo 51). Los principios pueden aplicarse mediante actos legislativos o ejecutivos (adoptados por la Unión en función de sus competencias y por los Estados miembros solamente en aplicación del Derecho de la Unión); por consiguiente, son importantes para los tribunales sólo cuando se trata de la interpretación o revisión de dichos actos. Sin embargo, no dan lugar a demandas directas de acciones positivas de las instituciones de la Unión o de las autoridades de los Estados miembros, lo que es coherente tanto con la jurisprudencia del Tribunal de Justicia (véase en particular la jurisprudencia sobre el «principio de cautela» que figura en el apartado 2 del artículo 174 del TCE (sustituido por el [artículo III-129] de la Constitución): sentencia del TPI de 11 de septiembre de 2002, T-13/99, Pfizer contra Consejo, que contiene numerosas referencias a la jurisprudencia anterior, así como una serie de sentencias sobre el artículo 33 (antiguo artículo 39) sobre los principios de la legislación agrícola, por ejemplo, la sentencia del Tribunal de Justicia en el asunto 265/85, Van den Berg, Rec. 1987, p. 1155: control del principio de estabilización de mercados y de confianza legítima) como con el planteamiento de los sistemas constitucionales de los Estados miembros respecto de los «principios», en particular en el ámbito del Derecho social. A título ilustrativo, ejemplos de principios reconocidos por la Carta incluyen, entre otros, los artículos 25 , 26 y 37. En determinados casos, un artículo de la Carta puede incluir elementos de un derecho y de un principio, por ejemplo, los artículos 23, 33 y 34. [Explicaciones actualizadas sobre el texto de la Carta de los Derechos Fundamentales (CONV 828/1/03 REV 1, 18/07/2003, p. 51)]. 
Aunque hay que felicitarse de que los responsables políticos que deben regir los futuros destinos de la UE se hayan posicionado tan claramente en relación con las Explicaciones (en el pasado lo hicieron con las elaboradas por la anterior Convención, pero de forma más sibilina ${ }^{34}$ ), no deja de ser cuestionable que un texto tan trascendental como el que ahora nos ocupa no haya merecido el debate que, por su importancia, merecía. Sí resulta claro, por el contrario, que ya no es tan fácil afirmar, como se hacía en la versión original de las Explicaciones, que «carecen de valor jurídico y tienen simplemente por objeto aclarar las disposiciones de la Carta». La alteración producida es menor si se contempla con cierta perspectiva. De un lado, porque aunque se le negara valor jurídico era evidente que el documento iba a ser tomado en consideración por los operadores jurídicos ${ }^{35}$. De otro, porque el Tribunal de Justicia tendrá la última palabra en la determinación del contenido esencial de los derechos fundamentales, ya que cualquier regulación en esta materia es, por esencia, limitada.

\section{LA EFICACIA DE LA PARTE II TECE: ¿UNOS DERECHOS Y PRINCIPIOS QUE NO LO SON?}

Los derechos fundamentales lo son en la medida en que son invocables ante un órgano judicial. Esta afirmación, predicable igualmente de los principios y que no precisa mayor justificación, explica que una de las cuestiones más debatidas en el seno del Grupo II haya sido la del alcance del control que, en esta materia, puede ejercer el Tribunal de Justicia.

En líneas anteriores, al hablar del contenido positivo de la nueva Carta, nos hemos ocupado de la limitada eficacia conferida a los principios, que guarda evidente parentesco con la ofrecida, en nuestro ordenamiento constitucional, a los principios rectores de la política social y económica.

Por tal motivo nos centraremos ahora en examinar el papel atribuido al Tribunal de Justicia como garante de los derechos fundamentales (entre los que se cuenta, bueno es recordarlo, el derecho a la tutela judicial efectiva — art. II-107 TECE—), valiéndonos para ello, una vez más, de los debates que han tenido lugar en el Grupo II.

Se ha cuestionado, en primer lugar, si era conveniente modificar el art. 46.d) del vigente Tratado de la Unión Europea, en el que se afirma que la competencia del Tribunal de Justicia se extiende, en materia de derechos fundamentales (entonces contemplados en el art. 6.2 TUE), a la actuación de las instituciones, «en la medida en que el Tribunal de Justicia sea competente con arreglo a los Tratados constitutivos» de la CE y de la UE. Lo que la Secretaria del Grupo sugiere, en su Nota de Reflexión, es que la Carta aparezca citada entre las disposiciones a las que se le aplica la jurisdicción del Tribunal de Justicia, y que se suprima la referencia realizada a las instituciones, porque también los Estados están afectados por la Carta cuando actúan en él marco del Derecho de la Unión (WG II 1, p. 13). Schooo, por su parte, propone una adaptación del art. 46.d) TUE, actuando el Tribunal de Luxemburgo como Tribunal Constitucional en el ámbito de Justicia y Asuntos de interior (cfr. WG II 8, p. 8).

Una gran preocupación ha venido marcada por las limitaciones que el Tribunal de

34 Cfr., del autor de estas líneas, «La eficacia...», p. 148, nota 76. 
medidas de aplicación del acto comunitario ${ }^{37}$. En esta línea de argumentación, el Defensor del Pueblo Europeo, Jacob Söderman, entiende que existe una obligación de los Estados miembros (ex art. 10 TCE) de que sus tribunales garanticen una tutela efectiva de los derechos reconocidos por el Derecho de la Unión (WG II 14, p. 2). Tal obligación se conecta, a juicio de otros oradores, con el principio de subsidiariedad, por lo que algunos miembros del Grupo se muestran interesados en que explicite en el nuevo Tratado que los Estados están obligados a establecer, en el plano nacional, vías de recurso eficaces con respeto a los derechos garantizados por el Derecho de la Unión (se retoma así la opción C del documento de trabajo 21) (WG II 14, p. 3).

Todas estas dudas se proyectan en el Informe Final del Grupo II que se caracteriza, en la materia que nos ocupa, por una marcada prudencia. El Grupo subraya que la incorporación de la Carta en la arquitectura constitucional [sic] de la Unión permite la utilización del actual sistema de recursos procesales para los ciudadanos (WG II 16, p. 15). Asimismo, apunta la posible necesidad de modificar las condiciones para el acceso directo de particulares al TJCE (art. 230.4 TCE) para garantizar la tutela judicial efectiva, superando las actuales lagunas que el citado precepto presenta. Sin embargo, «los debates del Grupo han puesto de manifiesto una opinión ampliamente difundida de que el actual sistema general de recursos, así como la «división del trabajo» entre los tribunales comunitarios y nacionales que conlleva, no debería verse profundamente alterada por la posible reforma del párrafo cuarto del artículo 230 del TCE. Algunos de los miembros aluden la posibilidad de incluir una disposición en el tratado sobre la obligación de los Estados miembros, ya existente en el plano jurisprudencial, de proporcionar recursos efectivos en relación con los derechos derivados de la legislación de la Unión» (WG II 16, pp. 15-16). En todo caso, tal cuestión supera el marco de los derechos fundamentales, puesto que la tutela debe predicarse para «todos» los derechos subjetivos. «El Grupo considera que esta cuestión y sus implicaciones institucionales deberán examinarse juntamente con otros temas (como son la limitación de la competencia del Tribunal en asuntos de interior y justicia o el control judicial de la subsidiariedad). Así pues, el Grupo se abstiene de formular recomendaciones concretas y remite la cuestión de la posible reforma del párrafo cuarto del artículo 230 del TCE, para un examen más detenido por parte de la Convención en el contexto oportuno» (W II 16, p. 16).

Es comprensible que el Grupo II recelara de proponer una medida tan atractiva como precipitada, cuál es permitir que los justiciables puedan impugnar disposiciones de carácter general, cuyas consecuencias prácticas no son difíciles de imaginar. Sin embargo, podían haber paliado tales consecuencias perturbadoras si se hubieran hecho eco de una propuesta realizada por diversas personalidades y que, salvo error u omisión, no ha sido trasladada al nuevo TECE. Se trataba de conferir legitimación activa al Defensor del Pueblo Europeo para que pudiera interponer demandas de asuntos individuales ante el Tribunal de Luxemburgo $^{38}$.

La idea que late, pues, es que las normas generales que, eventualmente, vulneren los derechos fundamentales de los justiciables sean impugnadas a través del recurso dirigido contra los actos de ejecución y aplicación adoptados por las autoridades nacionales. De esta forma, todos los tribunales nacionales deberán implicarse en la tutela de los derechos fun- 
Pero el asunto más debatido no ha sido éste, sino otro más esencial, referido a la eventual instauración de un mecanismo jurisdiccional que permitiera a los justiciables acceder ante el Tribunal de Luxemburgo para hacer valer sus derechos fundamentales y, con carácter general, hacer plenamente efectivo su derecho a la tutela judicial efectiva respecto de cualquier derecho o libertad [sic] garantizado por el Derecho de la Unión (art. II-107 TECE).

Como es sabido, el vigente art. 230.4 TCE solamente permite a las personas físicas o jurídicas que impugnen ante el Tribunal de Justicia las decisiones de las que sea destinatario y aquéllas otras que, aunque revistan la forma de un reglamento o de una decisión dirigida o otra persona, le afecten directa e individualmente. El último aserto impide la impugnación de reglamentos y directivas, incluso cuando lesionan derechos fundamentales.

No es de extrañar, a la vista de estos datos, que se hayan realizado diversas propuestas que aseguren una tutela judicial efectiva de los derechos fundamentales de la Unión.

La primera idea que se ha manejado en el seno del Grupo II es la eventual instauración de un recurso de amparo, siguiendo el modelo español o alemán (Verfassungsbeschwerde), que permitiera a los justiciables instar la protección de sus derechos fundamentales ante el Tribunal de Luxemburgo (WG II 1, p. 15).

Una gran mayoría de los oradores presentes en la sesión del Grupo II de 4 de octubre de 2002 se oponen a la creación de un recurso equivalente al amparo español, ya que se consideran suficientes las vías contenidas en los arts. 230 y 234 TCE (WG II 14, p. 2). Esta opinión se justifica en la idea de que la instauración de un recurso de amparo haría difícil diferenciar un nuevo recurso fundado en la violación de los derechos fundamentales de los demás recursos, dado que podrían alegarse estos derechos en la práctica totalidad de las demandas (WG II 1, p. 16). La misma opinión, contraria a la creación de un recurso de amparo, es expresada por Vassilios Skouris, Juez del TJCE (WG II 10, p. 9).

No es de extrañar, a la vista de estos datos, que Grupo II no recomiende a la Convención Europea, en su Informe Final, el establecimiento de un procedimiento especial ante el TJCE para la protección de los derechos fundamentales, tomando en cuenta las reservas expresadas por la mayor parte de sus miembros (WG II 16, p. 15).

La segunda medida propuesta consiste en flexibilizar las exigencias contenidas en el art. 230.4 TCE, haciendo posible la impugnación de disposiciones generales (reglamentos y directivas, en este momento) que lesionen los derechos subjetivos de los justiciables (WG II 1, p. 15). Los patrocinadores de esta iniciativa entienden que existen lagunas en el modelo actual, ya que el citado precepto impone que el acto afecte no solamente directa, sino individualmente al afectado, por lo que cierta reforma se impone (WG II 14, p. 2).

Sin embargo, otras voces desaconsejan optar por la apertura en la legitimación procesal prevista en el art. 230.4 TCE. Especialmente cualificada en este punto es la opinión del Juez del TJCE, Vassilios Skouris, que no considera deseable permitir que los particulares recurran normas generales (WG II 10, p. 9). Se afirma, en definitiva, que el Derecho comunitario cuenta con un sistema de recursos completo (WG II 1, p. 15), ya que el art. 230.4 TCE se combina con los recursos que pueden interponerse ante los órganos jurisdiccionales nacionales contra

36 El art. III-377 TECE aclara que dicha competencia no se extiende al control de validez o proporcionalidad de operaciones efectuadas por la policía o de alcance similar cuando dichos actos estén regulados por el Derecho interno. 
directamente si la disposición de que se trata afecta de manera cierta y actual a su situación jurídica restringiendo sus derechos o imponiéndole obligaciones. El número y la situación de otras personas igualmente afectadas por la disposición o que puedan serlo no son, a este respecto, consideraciones pertinentes» (considerando 51).

Sin embargo, que esta interpretación era cuestionable quedaba acreditado por la Sentencia del Tribunal de Justicia de la Comunidad Europea dictada pocas semanas más tarde, en el caso Unión de Pequeños Agricultores contra el Consejo de la Unión Europea (Sentencia de 25 de julio de 2002, recaída en el asunto C-50/00 P), en la que se afirma que el Tratado, mediante sus artículos 173 y 184 (actualmente artículo 241 [T]CE), por una parte, y mediante su artículo 177 , por otra, ha establecido un sistema completo de vías de recurso y de procedimientos destinado a garantizar el control de la legalidad de los actos de las instituciones, confiando dicho control al juez comunitario. En dicho sistema, sigue diciendo el Tribunal, las personas físicas o jurídicas que, debido a los requisitos de admisibilidad previstos en el artículo 173, párrafo cuarto, del Tratado, no puedan impugnar directamente actos comunitarios de alcance general, tienen la posibilidad, según los casos, de invocar la invalidez de tales actos bien de manera incidental ante el juez comunitario, en virtud del artículo 184 del Tratado, bien ante los órganos jurisdiccionales nacionales, e instar a estos órganos, que no son competentes para declarar por sí mismos la invalidez de tales actos, a que soliciten un pronunciamiento del Tribunal de Justicia sobre este extremo por medio de la cuestión prejudicial (Considerando 40). Son, pues, los Estados miembros, los encargados de asegurar la existencia y viabilidad de vías procesales para alcanzar tal fin (Considerandos 41 y 42), sin que el incumplimiento de tal obligación (art. 10 TCE) permita forzar la interpretación del art. 230.4 TCE (Considerando 44).

No es de extrañar que en fechas recientes el Tribunal de Justicia haya anulado la Sentencia dictada en su día por el Tribunal de Primera Instancia recaída en el asunto JégoQuéré contra la Comisión (Sentencia de 1 de abril de 2004, recaída en el asunto Comisón de las Comunidades Europeas contra Jégo-Quéré, C-263/02 P), reiterando, en lo esencial, los argumentos ya adelantados en la anterior Sentencia Unión de Pequeños Agricultores contra el Consejo, (cfr. párrafos 29 ss.) y observando, en definitiva, que por más que el art. 230.4 TCE deba interpretarse a la luz del derecho a la tutela judicial efectiva, los órganos jurisdiccionales comunitarios no pueden ignorar un requisito contemplado en el Tratado (que el particular resulte individualmente afectado) (párrafos 36 y 38).

Excluida, pues, la vía de la reinterpretación, solamente podía seguirse la vía de la reforma del art. 230.4 TCE. Y tal ha sido el camino elegido en el art. III-365.4 TECE, en el que se permite que toda persona física o jurídica interponga recurso de anulación contra los actos reglamentarios que le afecten directamente y que no incluyan medidas de ejecución. Este matiz se explica porque en tales supuestos en los que no hay medidas de ejecución o aplicación nacionales no es posible establecer ninguna acción judicial que permita alegar los derechos e intereses que se estimen lesionados por la normativa comunitaria. De esta forma se evitan eventuales paradojas, como es que el particular tuviera que asumir, como carga, para la defensa de sus derechos (también de los fundamentales), asumir el

37 WG II 1, p. 16; WG II 14, p. 2. En este último lugar se expresa cierta satisfacción y la inconveniencia de afectar al reparto de trabajo entre el juez nacional y el comunitario provocado por una eventual reforma, ibídem, pp. 2-3. 
damentales. Esta solución (que, por cierto, poco tiene que ver con el entendimiento que se hace del principio de subsidiariedad en el ordenamiento jurídico comunitario) evitará el colapso que la apertura del recurso previsto en el art. 230.4 TCE habría provocado en la jurisdicción comunitaria. Pero también se incurre en el riesgo de que los tribunales nacionales no confieran el mismo alcance a un determinado derecho fundamental de la Unión que el dispensado por otras jurisdicciones estatales. Será esencial, por este motivo, que el Tribunal de Justicia sea especialmente didáctico y alumbre el camino a seguir por las jurisdicciones nacionales cuando tenga la oportunidad, producida al amparo del recurso de anulación y, especialmente, de la cuestión prejudicial, de pronunciarse sobre el alcance de un determinado derecho fundamental.

Sin embargo, esta solución deja un frente abierto que no conviene descuidar, y del que es consciente el propio Grupo II. En aquellos supuestos en los que la legislación comunitaria se limita a formular una prohibición directamente aplicable a los particulares, sin requerir acto nacional alguno de interposición, la única reacción plausible a la medida, eventualmente limitadora de derechos fundamentales de la Unión, sería la de optar por el incumplimiento de la normativa comunitaria y discutir, al hilo de la sanción que, en su caso, se le impusiera, si la misma lesiona tales derechos (WG II 1, p. 16). Por tal motivo se considera preciso o una modificación del art. 230.4 TCE o, cuando menos, una reinterpretación de que debe entenderse por afectar «individualmente» (Cfr WG II 1, p. 16 y WG II 14, p. 2).

La referencia realizada a la reinterpretación guarda relación, muy probablemente, con la interesante Sentencia dictada por el Tribunal de Primera Instancia el 3 de mayo de 2002, en el asunto Jégo-Quéré et Cie SA contra la Comisión de las Comunidades Europeas (T-177-01). El recurrente es un armador irlandés que impugna diversos preceptos del Reglamento (CE) 1162/2001, sobre la recuperación de la población de merluza. Aunque el Tribunal admite que la disposiciones impugnadas son, por naturaleza, de alcance general (considerando 24), señala también que «ya no puede considerarse, a la luz de los artículos 6 y 13 del CEDH y del artículo 47 de la Carta de los derechos fundamentales, que los procedimientos previstos en los artículos 234 [T]CE, por un lado, y 288 [T]CE, párrafo segundo, por otro, garanticen a los justiciables un derecho de recurso efectivo que les permita impugnar la legalidad de disposiciones comunitarias de alcance general que afectan directamente a su situación jurídica» (considerando 47). A juicio del Tribunal «procede reconsiderar la interpretación estricta realizada hasta este momento del concepto de persona individualmente afectada en el sentido del artículo 230 [T]CE, párrafo cuarto» (considerando 50. En este punto son muy interesantes las consideraciones vertidas por el Abogado General Jacobs en relación con el asunto C-50/00 P, Unión de Pequeños Agricultores contra Consejo de la Unión Europea, presentadas el 21 de marzo de 2002, esp. Párrafos 82 ss., en las que propone entender que un demandante resulta individualmente afectado por un acto comunitario cuando este lesiona o puede lesionar sus intereses de manera sustancial (párrafo 102): «Habida cuenta de las consideraciones anteriores y para garantizar una protección jurisdiccional efectiva de los particulares, ha de considerarse que una persona física o jurídica queda individualmente afectada por una disposición comunitaria de alcance general que le afecta

38 En este sentido se expresaron Skouris, Juez del TJCE (WG II 10, p. 9) y Jacob Söderman, Defensor del Pueblo Europeo (WG II 14, p. 2). 
con la misma se consiga «el desarrollo armonioso de la jurisprudencia de los dos tribunales europeos de derechos humanos» (ibídem, p. 12). Este aserto es desafortunado porque equipara tribunales que cumplen distintas funciones y derechos que tienen distinta naturaleza.

Igualmente cuestionable y estéril es el empeño en afirmar que la adhesión de la Unión al Convenio no afecta al reparto competencial Unión/Estados miembros. Esta idea, repetida por eminentes juristas ${ }^{43}$, ha sido respaldada por el Grupo II en su reunión de 7 de octubre de 2002 (WG II 15, p. 1). En esta misma reunión, el Presidente del Grupo de Trabajo propone que se incluya en el informe final que la adhesión al CEDH no supondrá una modificación del reparto de competencias entre la Unión y los Estados miembros, asegurándose tal fin a través de diversos mecanismos (una aclaración en la base jurídica que autorice la adhesión y una disposición que incluya una declaración sobre la limitación de las competencias de la Unión que debería figurar en el mismo Tratado de adhesión). El CEDH solamente podría generar, así, «obligaciones positivas» dentro de los mentados límites (WG II 15, p. 1). Todas estas ideas encuentran fiel reflejo en el Informe Final: «Según opinión común del Grupo, el «ámbito de aplicación» jurídico de la adhesión de la Unión al CEDH se limitaría a las cuestiones en las que la Unión es competente; no entrañaría, pues, una ampliación de las competencias de la Unión, ni mucho menos el establecimiento de una competencia general de la Unión en materia de derechos fundamentales. Por lo tanto, únicamente se generarían obligaciones "positivas» de actuación de la Unión para dar cumplimiento al CEDH en la medida en que el tratado contemple competencias de la Unión que permitan tal actuación» (WG II 16, p. 13).

Es discutible que tal aclaración fuera precisa. La adhesión por parte de la Unión Europea al Convenio le obliga (si es que no lo estaba ya) a respetar, en el marco de sus competencias, los derechos allí recogidos. Es cierto que el Tribunal de Estrasburgo ha exigido en ocasiones determinados comportamientos activos o positivos por parte de los poderes públicos, pero es obvio que tal imposición solamente puede realizarse cuando dicho órgano público está legitimado para acometer dicha actuación que le reclama. De ahí que las recomendaciones de que se incluya en la posible base jurídica que autorice dicha adhesión tal previsión de que no se altera el reparto competencial Unión-Estados o de que se afirme la limitada competencia de la Unión en materia de derechos humanos en el Tratado de adhesión de la Unión al Convenio Europeo y, en su caso, en el de la Unión Europea (cfr. WG II 16, p. 13), son bastante más inermes de lo que podría pensarse a primera vista.

Un problema bien distinto al planteado hasta el momento es el de si el Tribunal de Estrasburgo puede y debe pronunciarse sobre qué autoridad (de la Unión o nacional) ha vulnerado un derecho fundamental. Aquí no se cuestiona el reparto competencial, sino a quien le corresponde pronunciarse sobre su articulación concreta. En este punto el Grupo II ha propuesto un mecanismo muy sugerente que evitaría que las instituciones del Consejo de Europa (especialmente, el Tribunal de Estrasburgo) deba pronunciarse sobre una cuestión interna de la Unión, y que está llamada a resolver, en última instancia, el Tribunal de Luxemburgo. Se trataría de que la Unión y, en su caso, los Estados afectados comparezcan como «codemandados» ante el Tribunal Europeo de Derechos Humanos, lo que podría garantizar que éste no se pronuncie entre el reparto de competencias entre la Unión y los Estados ${ }^{44}$.

Si la adhesión por parte de la Unión al CEDH no puede explicarse hoy por las caren- 
incumplimiento de preceptos comunitarios, por lo que debemos felicitarnos de la limitada pero significativa adición contenida en el art. III-365.4 TECE.

\section{LOS DERECHOS HUMANOS Y LA UNIÓN: LA ADHESIÓN AL CONVENIO EUROPEO DE DERECHOS HUMANOS.}

La Comisión ha planteado en diversas ocasiones la conveniencia de que las Comunidades Europeas se adhirieran al Convenio Europeo de Derechos Humanos ${ }^{39}$. Destaca, con luz propia, el difundido informe de Rudolf Bernhardt elaborado en 1979, elaborado al hilo del Memorándum de la Comisión, que originó un debate en el seno del Parlamento Europeo ${ }^{40}$. La Comisión reabre la cuestión con otra Comunicación en $1990^{41}$, aunque el debate generado en este caso se verá abruptamente interrumpido con el debatido y discutible Dictamen 2/94 del Tribunal de Justicia de las Comunidades Europeas, en el que se afirma que la Unión carece de competencia para adherirse al Convenio Europeo de Derechos Humanos ${ }^{42}$. No es de extrañar, a la vista de estos antecedentes, que el Consejo Europeo planteara a la CIG'2004 la cuestión de la adhesión de la Comunidad Europea al Convenio Europeo de los derechos humanos.

\subsection{Sentido de la vinculación de la Unión al Convenio Europeo de Derechos Humanos.}

Aunque en las siguientes líneas nos centraremos en el examen de esta cuestión es oportuno hacer notar que el sentido que, en la actualidad, pueda tener la adhesión por parte de la Unión Europea al Convenio Europeo de Derechos Humanos es, al menos, parcialmente distinto del que tuvo en el pasado. Lo cierto es que tanto antes como ahora los Estados miembros se han comprometido a respetar los derechos contenidos en el citado Tratado y sus protocolos anejos y adicionales, configurándolos como derechos subjetivos de sus justiciables, que pueden acudir ante los órganos de Estrasburgo.

Pero es también cierto que la pretensión de la Comisión de los años setenta de que se produjera tal adhesión pretendía que hubiera un catálogo de derechos humanos en el marco europeo, colmando así una laguna. Esta pretensión, comprensible en aquellos años, no es de recibo en la actualidad (cfr., en sentido contrario, WG II 1, p. 18), ya que el Tratado incluye una muy amplia declaración de derechos, a cuyo examen hemos dedicado las líneas anteriores.

Este dato debe servirnos para poner en cuestión alguna de las afirmaciones que se han repetido durante los debates de la Convención y, sobre todo, para proponer cuál es, siempre a nuestro juicio, el recto entendimiento de la cuestión. Comenzando por el primer extremo apuntado, es ingenuo (e incluso pernicioso, como luego diremos) pensar que la adhesión por parte de la Unión del Convenio Europeo provocará una plena armonización entre los derechos fundamentales de la Unión y los recogidos en el Convenio Europeo de Derechos Humanos (cfr. art. II-112.3 TECE). Si bien puede apoyarse la misma en la voluntad de lanzar un mensaje político de que hay una coherencia entre la Unión y la Europa en sentido amplio en materia de derechos humanos (WG II 16, p. 11), no es tan seguro que 
ción europea (WG II 1, p. 21). Tal temor desaparece si se recuerda que el único alcance de la jurisdicción de Estrasburgo es la constatación de que la Unión y/o los Estados (si asume el mecanismo de actuar ambos como codemandados) ha(n) desconocido alguno de los derechos a cuyo respeto se había(n) comprometido.

La decisión de que la Unión Europea se vincule al respeto del CEDH no resuelve todos los problemas. La primera duda que cabe plantearse es cómo articular, en términos jurídicos, dicha implicación, y aquí se han manejado distintas propuestas.

\subsection{Formas de ARTiCUlar EL CONTROL DE ESTRAsburgo.}

\subsubsection{La adhesión.}

La primera, y más sencilla, es defender, simplemente, la adhesión de la Unión al $\mathrm{CEDH}$. Como se advierte desde un primer momento, si se sigue este camino será preciso operar modificaciones tanto en el plano del Derecho comunitario originario como en que rige el Convenio Europeo de Derechos Humanos. Por lo que atañe a los Tratados comunitarios, sería preciso incorporar una habilitación que permitiera a la Unión acometer la adhesión al CEDH (a tenor de lo previsto en el citado Dictamen 2/94 del Tribunal de Luxemburgo). Por lo que afecta al Consejo de Europa, sería precisa la reforma del CEDH que ahora contempla como eventuales partes contratantes a los Estados miembros del Consejo de Europa (cfr. WG II 1, p. 19).

En el Informe Final del Grupo II se recomienda «que se incluya en el lugar adecuado del nuevo tratado constitucional una base jurídica que autorice a la Unión a adherirse al CEDH. La redacción de dicha base jurídica podría ser bastante sencilla» (WG II 16, p. 13). Debería constar que la firma y celebración del Tratado de adhesión requerirían una decisión unánime del Consejo y el dictamen del Parlamento Europeo (ídem), y que la misma ni altera el reparto de competencias entre la Unión y los Estados miembros (nota 1 de al misma página) ni supone un reconocimiento de una competencia general [sic] de la Unión en el ámbito de los derechos fundamentales ${ }^{47}$. Por tal motivo, tal y como se sugiere en el

39 Abre esta preocupación el Informe de la Comisión de 4 de febrero de 1976 dirigido al Parlamento Europeo sobre la protección de los derechos fundamentales a través de la creación y el desarrollo del Derecho comunitario (Bull. CCEE, supplément 1976-5).

40 Dicho informe acompaña al Memorándum de la Comisión de 4 de abril de 1979 sobre la adhesión de las Comunidades Europeas al CEDH (Bull. CCEE, supplément 1979-2). De esta época merecen ser igualmente recordadas las Resoluciones del Parlamento Europeo de 27 de abril de 1979 (JOCE C 127, de 21 de marzo de 1979, pp. 69-70) y de 29 de octubre de 1982 sobre el Memorándum presentado por la Comisión en 1979 (JOCE C 304, de 22 de noviembre de 1982, pp. 253-254).

41 Comunicación de 19 de noviembre de 1990 sobre la adhesión de la Comunidad al CEDH [SEC(90)2087 final]. El Parlamento Europea se pronunciará sobre esta cuestión en la Resolución de 18 de enero de 1994 sobre la adhesión de la Comunidad al CEDH (DOCE C 44, de 14 de febrero de 1994, pp. 32-34) y, especialmente, en el Informe de 17 de mayo de 1995 dirigido al Grupo de Reflexión sobre el funcionamiento del Tratado de la Unión Europea en la perspectiva de la CIG'96: Realización y desarrollo de la Unión (DOCE C 151, de 19 de junio de 1995, pp. 56-67).

42 El dictamen fue solicitado por el Consejo (cfr. DOCE C 174 de 25 de junio de 1994, p. 8) y fue emitido con el número 2/94 el 28 de marzo de 1996 (Rec. 1996\1, pp. 1759-1790). 
cias formales del modelo de protección de los derechos fundamentales en la Unión Europea, encuentra otros asideros, pragmáticos y sustanciales, que merece la pena retener, aunque sea brevemente.

Tal adhesión serviría, en primer lugar, para resolver un problema eminentemente práctico. Nos guste o no, el Tribunal de Estrasburgo está en la línea de someter a su enjuiciamiento los actos de la Unión Europea que lesionan los derechos contenidos en el Convenio (en sentido lato). Un buen resumen de la posición mantenida por el Tribunal de Estrasburgo sobre el Derecho de la Unión se contiene en la Sentencia Koua Poirrez c. Francia, de 30 de septiembre de 2003, que se mueve en la misma dirección de resoluciones anteriores ${ }^{45}$. Parece absurdo que, ejerciéndose este control de facto, la Unión renuncie a defenderse ante el Tribunal de Estrasburgo.

Pero es que, además y en segundo lugar, la adhesión por parte de la Unión del CEDH supondría la implementación de un (siempre deseable) control externo en materia de derechos humanos. Estamos así, en presencia, de un control complementario al establecido dentro de la propia Unión. Esta idea, correctamente expresada en el primer documento de reflexión del Grupo II (las propuestas de la incorporación de la Carta y de la adhesión al $\mathrm{CEDH}$ no son propuestas alternativas, sino complementarias, porque se trata de añadir un control externo, con independencia de que la Unión se dote de su propio catálogo derechos fundamentales, WG II 1, p. 17), se ha trasladado de forma más confusa al Informe Final (porque se dice que ambas pretenden garantizar el pleno respeto de los derechos fundamentales, cfr. WG II 16, p. 12, siendo conveniente separar, como cuestiones escindibles que son, la protección de estos derechos y de los derechos humanos).

Este entendimiento de la cuestión permite superar los dos argumentos manejados para criticar la eventual sumisión del Derecho comunitario al Tribunal de Estrasburgo. Se dice, en primer lugar, que la instauración de tal control es incompatible con la autonomía del Derecho comunitario y cuestiona el lugar que le corresponde al Tribunal de Luxemburgo (WG II I, pp. 18-20). El alegato es inconsistente, pero no porque se diga que el Tribunal de Estrasburgo actuaría como una jurisdicción especializada o porque respete un cierto margen de apreciación al Tribunal de Luxemburgo (Marc Fishbach) (cfr. WG II 1, p. 20 y WG II 10, p. 3, respectivamente), sino porque, como acertadamente se indica en el Informe Final, la posición del TJCE sería análoga a la actual posición de los tribunales constitucionales o supremos nacionales respecto del Tribunal de Luxemburgo (WG II 16, p. 12). Conservará el monopolio para resolver las cuestiones de Derecho de la Unión (también de las referidas a los derechos fundamentales) y pronunciarse acerca de la validez de los actos de la Unión. El Tribunal de Estrasburgo sería, simplemente, un tribunal que ejerce un control externo sobre las obligaciones de Derecho internacional de la Unión derivadas de su adhesión al $\mathrm{CEDH}^{46}$.

La segunda reserva que puede oponerse a la eventual adhesión de la Unión al CEDH trae causa de que se encuentra censurable que la Unión se someta al control de jueces no nacionales de su territorio, que podrían no comprender bien la especificidad de la integra-

43 Marc Fischbach, juez del TEDH, entiende que la adhesión de la UE no altera el reparto de competencias entre la Unión y los Estados miembros (WG II 10, p. 5). Vassilios Skouris, Juez de Luxemburgo, tampoco vé que tal medida afecte ni a la autonomía del Derecho comunitario ni al reparto de competencias entre la Unión y los Estados miembros (WG II 10, p. 9). 
niente: se opone «a la norma — que el Tribunal de Justicia considera emanada del principio de autonomía del Derecho comunitario - de que los jueces del Tribunal de Justicia no deberían deliberar simultáneamente en otros foros en los que debieran interpretar disposiciones idénticas a las del Derecho comunitario pero atendiendo a planteamientos, métodos y conceptos diferentes» ${ }^{48}$. A nuestro juicio, hay un inconveniente mayor en esta solución. En líneas anteriores hemos señalado que los derechos fundamentales comunitarios pueden verse sometidos a límites específicos, que no tienen porque ser reconocidos por el Tribunal de Estrasburgo. La uniformidad total es, por los argumentos esgrimidos supra, una mera muestra de voluntarismo.

La última técnica propuesta sería la instauración de un recurso por parte de los particulares ante el actual TEDH (WG II 1, p. 26). Esta propuesta se relaciona con lo que Piris denomina adhesión funcional (cfr WG II 8, p. 6), solución respecto de la que el Presidente del Grupo muestra su escepticismo (WG II 10, p. 3). En el mismo sentido se expresa el juez del TEDH Marc Fischbach, por entender que es contrario al principio de garantía colectiva, ya que no habría representante del Derecho de la Unión, lo que es esencial dada la especificidad del Derecho comunitario y de la Unión y la necesidad de garantizar un desarrollo armónico del mismo a la vista del CEDH (WG II 10, p. 6). Se trataría de que la Unión se someta al control del Tribunal de Estrasburgo, pero sin participar en las negociaciones relativas a las modificaciones futuras del CEDH (en sentido amplio), lo que implicaría, a juicio de la presidencia, dificultades de principio en cuanto a la autonomía del Derecho comunitario y problemas concretos (WG II 1, p. 25), cual es verse sometido a un Derecho que formalmente no forma parte de la UE y que, por otra parte, la CE/UE no recibiría en el sistema de Estrasburgo un trato idéntico a los demás signatarios del CEDH (WG II 1, p. 26).

A la vista de los datos aportados, no debe sorprender al lector que el Informe Final del Grupo II desaconseje los mecanismos alternativos a la adhesión formal de la Unión al CEDH (WG II 16, p. 15).

\subsection{LAS DECISIONES DE LA CONVENCIÓN Y DE LA CIG’2004.}

La decisión del Grupo II de optar por la adhesión por aparte de la UE al CEDH exige

44 WG II 16, p. 14. Sobre esta cuestión, cfr. WD 008, párrafos 57-62. Ya en el primer documento del Grupo de Trabajo se aludía a la posibilidad de que la CE/UE se asociara a un Estado miembro en calidad de parte demandada y responsable solidaria, y viceversa, junto con la inclusión de una declaración que subraye que únicamente la CE/UE y los Estados miembros estarán facultados para pronunciarse sobre el reparto de competencias a tenor de sus procedimientos internos (WG II 1, p. 22, y nota 2). Por su parte, el Juez Fischbach del TEDH alude al mecanismo del «codefenson» desarrollado por el Comité Director de los Derechos Humanos $(\mathrm{CDDH})$ del Consejo de Europa, mecanismo que permite que un Estado miembro demandado tenga la posibilidad de invitar a la Unión a constituirse parte en el procedimiento como «codemandada» si considera que el asunto afecta a la responsabilidad de la Unión y viceversa. La Sentencia se aplicaría solidariamente a ambos codemandados, sin pronunciarse sobre el reparto de responsabilidades entre ellos (WG II 10, p. 5).

45 Pueden traerse a colación las SSTEDH Cantoni c. Francia, de 15 de noviembre de 1996, y Matthews c. Reino Unido, de 18 de febrero de 1999, así como las Decisiones Société Guérin Aumobiles, de 4 de julio de 2000, y Senator Lines, adoptada por la Gran Sala el 10 de marzo de 2004. Es oportuno recordar, igualmente, que el asunto Bosphorus airways c. Irlanda ha sido admitido a trámite. 
Informe Final, la Unión no se convertiría en miembro del Consejo de Europa, ni sería un interlocutor político general de Estrasburgo, sino que se integraría únicamente en el sistema específico de control judicial de los derechos humanos establecido por el CEDH. Habría un juez del TEDH elegido a tenor de la Unión, y otro representante en el cometido específico del Comité de Ministros de velar por la ejecución de las sentencias de conformidad con el art. $46 \mathrm{CEDH}$, pero no en las funciones generales del Comité ajenas al CEDH (aunque ya asista, sin derecho de voto) (WG II 16, p. 14).

Sin embargo, con el fin de conjurar que la Unión pueda disponer de una competencia general en materia de derechos humanos, se han propuesto igualmente otras formulas, alternativas a la adhesión, destinadas a garantizar la coherencia entre el Derecho de la Unión y el CEDH.

\subsubsection{Otras fórmulas alternativas.}

Se han debatido, esencialmente, y además de la adhesión, tres vías distintas con el fin de que el Derecho de la Unión respete los derechos humanos contenidos en el CEDH.

El primero de ellos es el mecanismo del traslado o consulta, que permitiría al Tribunal de Luxemburgo la posibilidad de plantear al Tribunal de Estrasburgo una cuestión de interpretación del CEDH (WG II 1, p. 23). Esta medida, que se dice puede ser complementaria o alternativa a la adhesión, podría asegurar cierta coherencia en la actuación de ambos tribunales, aunque no puede olvidarse que, como ya hemos afirmado, el catálogo de los derechos fundamentales es autónomo y distinto del contenido en el CEDH. La propia presidencia del Grupo II es consciente de los inconvenientes derivados de optar por esta vía (prolongación considerable de la resolución del conflicto jurídico; posibles situaciones incómodas para el Tribunal de Luxemburgo, por decidir no plantear la consulta y verse después controlado por Estrasburgo; efectos de la vinculación política de los dictámenes del TEDH aunque se consideren jurídicamente no vinculantes; mezcla indebida de sistemas jurídicos, que implican una mayor injerencia del Tribunal de Estrasburgo, ya que se pronunciaría antes que el de Luxemburgo....-WG II 1, p. 23-), dato que unido a las exigencias formales que su asunción conllevaría (sería preciso un protocolo especial anejo a los Tratados CE/UE y modificaciones del CEDH, puesto que estamos ante una función distinta del TEDH —WG II 1, p. 24-), hacen que esta opción no cuente con excesivos apoyos. Por poner solamente un ejemplo de tales reservas, es posible recordar que el Juez del TEDH Marc Fishbach la desaconseja porque provocaría dilaciones en la resolución de los asuntos y porque conferiría una competencia [sic] en favor del Tribunal de Luxemburgo de la que carecen los Tribunales Supremos nacionales (WG II 10, p. 6).

Podría optarse, en segundo lugar, por la instauración de una Sala Común, compuesta por jueces de Luxemburgo y Estrasburgo, lo que aseguraría una uniformidad absoluta (WG II 1, p. 25). Esta idea presenta, a juicio de la presidencia del Grupo II, un gran inconve-

46 Ídem. Sobre estas cuestiones cfr WG II 1, p. 18 ss.; WG II 10, pp. 3 y 9 y el Dictamen 1/91 del Tribunal de Justicia de las Comunidades Europeas, de 14 de diciembre de 1991, sobre el proyecto de Acuerdo entre la Comunidad y los países de la Asociación Europea de Libre Comercio sobre la creación de un Espacio Económico Europeo. 
6.1. Mandato del Grupo«Carta» (CONV 72/02, De 31/05/2002).

\subsection{Documentos Elaborados En EL SENO DEL GRUPO II:}

- Fórmulas y consecuencias de la integración de la Carta de los derechos fundamentales en los Tratados y de la adhesión de la Comunidad o de la Unión al Convenio Europeo para la protección de los derechos humanos (CEDH) (CONV 116/02; WG II 1; de 18/06/2002).

- Orden del día de la reunión de 25/06/2002 (CONV 121/02; WG II 2; de 19/06/2002).

- Calendario de reuniones (CONV 163/02; WG II 3; de 18/09/2002).

- Nota resumida de la reunión de 25/06/2002 (CONV 164/02; WG II 4; de 28/06/2002).

- Orden del día de la reunión de 12/07/2002 (CONV 172/02; WG II 5; de 03/07/2002).

- Orden del día provisional de la reunión de 23/07/2002 (CONV 196/02; WG II 6; de 15/07/2002).

- Nota de síntesis de la reunión de 12/07/2002, presidida por el Comisario D. António Vitorino (CONV 203/02; WG II 7; de 18/07/2002).

- Nota de síntesis de la reunión de 23/07/2002, presidida por el Comisario D. António Vitorino (CONV 223/02; WG II 8; de 31/07/2002).

— Orden del día de la reunión de 17/09/2002 (CONV 244/02; WG II 9; de 9/09/2002).

- Nota de síntesis de la reunión de 17/09/2002, presidida por el Comisario D. António Vitorino (CONV 295/02; WG II 10; de 26/09/2002).

— Orden del día de la reunión de 04/10/2002 (CONV 306/02; WG II 11; de 30/09/2002).

- Orden del día de la reunión de 07/10/2002 (CONV 309/02; WG II 12; de $01 / 10 / 2002$ ).

- Orden del día de la reunión de 21/10/2002 (CONV 348/02; WG II 13; de $16 / 10 / 2002)$.

- Nota resumida de la reunión de 04/10/2002, presidida por el Comisario António Vitorino (CONV 350/02; WG II 14; de 17/10/2002).

- Nota resumida de la reunión de 07/10/2002, presidida por el Comisario António Vitorino (CONV 351/02; WG II 15; de 17/10/2002).

- Informe final del Grupo II (CONV 354/02; WG II 16, de 22/10/2002).

— Resumen de la reunión mantenida el 21/10/2002 (CONV 360/02; WG II 17; de

47 WG II 1, p. 22. Esta formula contrasta con la contenida en el Informe Final, en el que se afirma que la la Convención sólo deberá decidir si procede introducir en el nuevo tratado una disposición constitucional que «faculte» a la Unión para adherirse al CED. Corresponderá a las Instituciones, en particular al Consejo por unanimidad, determinar los plazos, forma y alcance de la misma. Pese a esto, «todos» los miembros del Grupo apoyan con firmeza o bien están dispuestos a estudiar con ánimo favorable la creación de una autorización constitucional que faculte a la Unión para adherirse al CEDH (WG II 16, p. 11). 
plantearse algunas dudas añadidas, sobre el alcance material de la misma y las eventuales reservas que pudieran realizarse al citado Convenio (en sentido amplio). Ya hemos señalado que el Grupo de Trabajo entiende que la eventual adhesión por parte de la Unión al CEDH no debe traducirse en un aumento de las competencias de la Unión Europea (WG II 10, p. 2). Pero tampoco debe afectar, a juicio del Grupo de Trabajo, a las distintas reservas que los Estados miembros de la Unión han realizado respecto del Convenio y sus protocolos (ídem). Esta última idea es reiterada por el Presidente posteriormente, en la reunión de 7 de octubre de 2002 (GW II 15, p. 2) y se traslada, finalmente, al Informe Final.

En este se afirma, en efecto, que la posición de cada uno de los Estados miembros respecto al CEDH (decisiones sobre la ratificación de determinados protocolos adicionales, o reservas realizadas, o su derecho a adoptar medidas de derogación específicas) no se verá afectada por la adhesión de la Unión. (WG II 16, p. 14). Esto supone, de un lado, que es al Consejo a quien corresponde definir, por unanimidad, los protocolos adicionales a los que debería adherirse la Unión, así como las reservas que deba formular en su propio nombre (WG II 16, p. 14). Esto implica, de otro lado, que las reservas individuales formuladas por los Estados miembros respecto al CEDH y sus protocolos adicionales, así como el derecho de éstos a adoptar medidas de derogación específicas (art. 15 CEDH) no se ven afectados por la adhesión (WG II 16, p. 15).

La Convención ha asumido como propia la sugerencia realizada por el Grupo de Trabajo, que encuentra reflejo en el art. I-9.2 TECE, precepto en el que se afirma que «La Unión procurará adherirse al Convenio Europeo para la Protección de los Derechos Humanos y de las Libertades Fundamentales». Tal mandato se ve rodeado de la consabida cautela de que dicha «adhesión no afectará a las competencias de la Unión que se definen en la Constitución».

Ningún reproche crítico merece el primer aserto del citado precepto. Es obvio que la Unión Europea saldrá reforzada por su adhesión a un control externo en materia de derechos fundamentales. Tal apuesta encierra algunas virtudes y determinados riesgos. La principal ventaja que tal medida puede ocasionar es que el Tribunal de Justicia de la Unión Europea empiece a tomarse un poco más en serio los derechos fundamentales de la Unión, y se anime a protegerlos de forma más generosa. El riesgo, que deriva en mayor medida de otros preceptos contenidos en el TECE (arts. I-9.3, y determinadas disposiciones generales de la Carta de los derechos) es que el Tribunal de Luxemburgo realice una construcción mimética de los derechos fundamentales comunitarios a la vista de los recogidos en el $\mathrm{CEDH}$, olvidando que los primeros se reconocen y articulan, como los constitucionales, en un determinado ámbito espacio-cultural. En todo caso, es claro que tras los cambios normativos que ahora se anuncian y esperan los siguientes pasos en la materia vendrán de la mano de las jurisdicciones de Estrasburgo y Luxemburgo. Esperemos que se orienten en la buena dirección...

\section{ANEXO: LISTADO DE DOCUMENTOS DE LA CONVENCIÓN Y DE LA CIG'2004 ${ }^{49}$ :}


- Interventions de MM. Schoo, Piris et Petite lors de la réunion du groupe, le 23 juillet 2002 (WG II WD 013, 02/08/2002).

- «Clarifying Horizontal Articles», note by Mr Neil MacCormick, alternate member of the Convention (WG II WD 014, 05/09/2002).

- «Proposals for Accession of the EU to the European Convention on Human Rights», document by Mrs. Lena Hjelm-Wallén, member of the Convention, and Mr. Ingvar Svensson, alternate member of the Convention (WG II WD 015, 13/09/2002).

— «The search for the«missing horizontal» in the Charter of Rights — an interim report on progress», paper by Baroness Scotland of Asthal, alternate member of the Convention (WG II WD 016, 13/09/2002).

- «Possibilité d’invoquer la charte des droits fondamentaux et amélioration de la protection des droits individuels», document de M. Jürgen Meyer, membre de la Convention (WG II WD 017, 13/09/2002).

- «Accession by the European Union to the European Convention on Human Rights», paper by Mr Esko Helle, alternate member of the Convention, supported by Mr Vytenis Andriukaitis, member of the Convention, and Mr Neil MacCormick, alternate member of the Convention (WG II WD 018, 16/09/2002).

- Audition de M. le juge Vassilios Skouris le 17 septembre 2002 (WG II WD 019, 20/09/2002).

— «Le système des voies de recours judiciaires» note rédigée par Sir Francis Jacobs, Avocat général à la Cour de justice des Communautés européennes (document présenté par M. Ben Fayot, membre de la Convention) (WG II WD 020, 27/09/2002).

— «Recours juridictionnels effectifs et accès des particuliers à la Cour de justice des Communautés européennes», document de M. António Vitorino, Président du Groupe de Travail et membre du Praesidium (WG II WD 021, 01/10/2002).

— «Projet de constitution de l'Union européenne», document de Mme Elena Paciotti, membre suppléante de la Convention (WG II WD 022, 03/10/2002).

- «Compromise proposals concerning drafting adjustments in the horizontal articles», document by Mr. António Vitorino, Chairman of the Working Group and member of the Praesidium (WG II WD 023, 04/10/2002).

- «Comments on horizontal articles of the Charter», document by Mr. Vytenis Andriukaitis, member of the Convention (WG II WD 024, 09/10/2002).

— WG II WD 025 —WG II — Projet de rapport final 14/10/2002 WG II WD 025 -WG II- Projet de rapport final (WG II WD 025, 14/10/2002).

- Comments to the Draft final report (WG II WD 026, 18/10/2002).

- Consultation concernant la version actualisée et consolidée des explications relatives à la Charte (WG II WD 027, 03/06/2003).

- Reactions of Working Group members to Document WD 027 (consolidated and updated Explanations on the Charter) (WG II WD 028, 12/06/2003).

\subsection{Otros documentos de la Convención y de LA CIG'2004:}


23/10/2002).

\subsection{Documentos de trabajo (WORKIng DOCuments) DEL Grupo II:}

- «Modalities and consequences of incorporation into the Treaties of the Charter of Fundamental Rights and accession of the Community/Union to the ECHR», paper by by Mr. Bobby McDonagh, alternate member of the Convention (WG II WD 1, 24/06/2002).

- Observations de Mme Elena Paciotti, membre suppléante de la Convention, au Groupe de Travail II (WG II WD 2, 28/06/2002).

- «La relation entre la Charte et les compétences de l'Union», document de M. António Vitorino (Président du Groupe de Travail et membre du Praesidium) (WG II WD 3, 05/07/2002).

- «The«missing» horizontal article in the Charter of Rights», Paper by Baroness Scotland of Asthal, alternate member of the Convention (WG II WD 004, 09/07/2002).

- «Legal status of the Charter of Fundamental Rights of the European Union», paper by Mr. Vytenis Andriukaitis, member of the Convention (WG II WD 005, 09/07/2002).

— «Réponses aux questions posées dans le chapitre II du doc.», document de Mme Elena Paciotti, membre suppléante de la Convention (WG II WD 006, 12/07/2002).

- «Answers to some of the questions raised during the first meeting of the Working Group», paper by Mr. Vytenis Andriukaitis, member of the Convention (WG II WD 007, 12/07/2002).

— «Etude menée au sein du Conseil de l'Europe sur les questions juridiques et techniques d'une éventuelle adhésion à la $\mathrm{CEDH»,} \mathrm{rapport} \mathrm{circulé} \mathrm{par} \mathrm{M.} \mathrm{António}$ Vitorino (WG II WD 008, 18/07/2002).

- «Adaptation rédactionnelle éventuelle de l'article 51, paragraphe 2 et de l'article 52, paragraphe 2, de la Charte; question des«dédoublements» dans la Charte», document de M. António Vitorino, Président du Groupe de Travail et membre du Praesidium, (WG II WD 009, 18/07/2002).

- «How should the«replication» arising from the fact that some articles of the Charter repeat rights already enshrines in the EC Treaty be dealt with?», document by Mr. Alexander Arabadjiev, alternate member of the Convention (WG II WD 010, 22/07/2002).

- «Answers to questions in doc. CONV 116/02, concerning the incorporation of the Charter into the Treaties and the accession of the Union/Community to the ECHR», document by Mr. Janusz Trzcinski, alternate member of the Convention (WG II WD 011, 23/07/2002).

— «The relationship between the Charter and the ECHR», paper by Mr. René van der Linden, member of the Convention (WG II WD 012, 25/07/2002).

49 En negrita se indica la referencia abreviada a través de la que, en su caso, han sido citados en el texto. 
- Explicaciones actualizadas sobre el texto de la Carta de los Derechos Fundamentales (CONV 828/1/03 REV 1, 18/07/2003).

- Tratado por el que establece una Constitución para Europa (CIG 87/04, de 6 de agosto de 2004). 
